\title{
LOS DERECHOS HUMANOS EN ESTADOS EXCEPCIONALES Y EL CONCEPTO DE SUSPENSIÓN DE DERECHOS FUNDAMENTALES
}

GUILLERMO ESCOBAR ROCA 
SUMARIO:

1. PLANTEAMIENTO: «SUSPENSIÓN DE DERECHOS», UN CONCEPTO EN CONSTRUCCIÓN. 2. CONSEJO DE EUROPA: 2.1. El Convenio Europeo de Derechos Humanos en la interpretación del Tribunal de Estrasburgo. 2.2. La doctrina de la Comisión de Venecia y el más reciente soft law europeo. 3. NACIONES UNIDAS: 3.1. El Pacto Internacional de Derechos Civiles y Políticos y su desarrollo y aplicación por su Comité de supervisión. 3.2. Algunos recientes documentos del soft law de las Naciones Unidas. 4. ORGANIZACIÓN DE ESTADOS AMERICANOS: EN ESPECIAL, LA DOCTRINA DE LA CORTE INTERAMERICANA DE DERECHOS HUMANOS. 5. CONSECUENCIAS PARA EL DERECHO CONSTITUCIONAL. 


\title{
LOS DERECHOS HUMANOS EN ESTADOS EXCEPCIONALES Y EL CONCEPTO DE SUSPENSIÓN DE DERECHOS FUNDAMENTALES
}

\author{
GUILLERMO ESCOBAR ROCA ${ }^{1}$ \\ Universidad de Alcalá
}

\section{PLANTEAMIENTO: «SUSPENSIÓN DE DERECHOS», UN CONCEPTO EN CONSTRUCCIÓN}

En este trabajo se analiza la incidencia del Derecho internacional de los derechos humanos sobre el régimen constitucional de los derechos fundamentales en los estados excepcionales $^{2}$. Una de las tareas principales de la teoría de los derechos es la construcción de conceptos que resulten útiles para la dogmática y la práctica jurídica ${ }^{3}$, para lo cual debe partirse, cuando los conceptos se encuentran expresamente previstos en el Derecho vigente, de los propios textos normativos y de su interpretación por los órganos públicos competentes para ello, sin perjuicio de su refinamiento, y sin descartar (obviamente, si se argumentan bien) las propuestas de reconstrucción del concepto, alternativas a las definiciones jurisprudenciales. También la teoría debe advertir sobre la presencia de conceptos vacíos, inútiles o redundantes, proponiendo en estos casos su depuración ${ }^{4}$. Buena parte de las discusiones entre los juristas trae causa de un diferente

Director del PRADPI y Profesor Titular de Derecho Constitucional, acreditado como Catedrático. Universidad de Alcalá - Facultad de Derecho. C/ Libreros 27. 28801 Alcalá de Henares. E-mail: guillermo.escobar@uah.es

2 Este término genérico es el utilizado en la doctrina española para referirse a los estados de alarma, excepción y sitio, que equivaldría al inglés states of emergency.

3 Atendiendo a las funciones de los conceptos jurídicos enumeradas en S. DÍEZ SASTRE (2018), La formación de conceptos en el Derecho público, Madrid, Marcial Pons, pp. 142-151, en este trabajo se va a proponer básicamente un concepto vinculado a una teoría (implícita) de los derechos, que pretende ser a la vez creativo (alternativo al uso habitual del término), aunque relativamente (pues se apoya en el Derecho internacional), y prescriptivo, en tanto aspira a incidir en la realidad.

4 La inspiración es obviamente la famosa navaja de Ockham. Serían conceptos inútiles, p. ej., los demasiado apegados a un determinado contexto histórico, y ya superado, como «derechos públicos 
uso de los conceptos; aclarados estos, quizás la controversia se reconduzca a sus justos términos, e incluso concluya antes de lo previsto. Así podría a mi juico suceder con el debate actual en nuestro país sobre el estado de alarma relativo a la crisis del COVID$19^{5}$, de ahí la pertinencia de esta modesta contribución.

Uno de los conceptos específicos de la teoría y dogmática de los derechos fundamentales es «suspensión de derechos». El concepto no puede eludirse, al menos en España, pues aparece expresamente en el artículo 55 CE y en la legislación que lo desarrolla. El Tribunal Constitucional solo se ha ocupado de este concepto obiter dicta ${ }^{6}$, y en todo caso no es la función principal de los tribunales, siempre condicionados por

subjetivos» o «garantías institucionales», o los demasiado específicos de un ordenamiento concreto, como «derechos civiles» (Estados Unidos), «libertades públicas» (Francia) o «derechos inviolables» (Italia). Los conceptos utilizados por el constituyente (p. ej., «contenido esencial», del que hablaré más adelante) nunca deberían ser superfluos, por aquello del «legislador racional». Luego encontramos conceptos doctrinales típicamente hispánicos, que además son peligrosos, como «derechos de configuración legal», o «derechos que son principios»: un análisis desde una filosofía del lenguaje bastante elemental demostraría (no es este el momento) que estos dos últimos son internamente contradictorios, o al menos lo son con el concepto prácticamente unánime de «derechos fundamentales»: exigibles directamente ante los tribunales, inclusive ante el legislador ausente, y en todo caso frente a éste.

5 El estado de alarma fue declarado inicialmente por el RD 463/2020, de 14 de marzo, varias veces modificado, y ha dado lugar a un amplio debate entre nuestros especialistas en Derecho público, sobre todo en los medios de comunicación, y que aquí no podemos abordar en su totalidad. Por lo que a este trabajo interesa, en síntesis se discute si las medidas adoptadas implicaron una suspensión o una limitación de derechos fundamentales; para una síntesis del debate inicial, F. J. DÍAZ REVORIO (2020), «A vueltas con la suspensión de los derechos fundamentales», Almacén de Derecho, disponible en línea. El 6 de mayo de 2020 el Tribunal Constitucional admitió a trámite el recurso de inconstitucionalidad presentado por más de cincuenta diputados del Grupo Parlamentario VOX contra los arts. 7, 9, 10 y 11 del RD 463/2021.

6 Las únicas ocasiones donde se analiza con cierto detalle la suspensión de derechos (SSTC 25/1981, 199/1987 y 71/1994) se refieren al art. 55.2, que queda fuera de este trabajo, y en todo caso el Tribunal no se preocupa de definir el concepto. En cuanto a la STC 83/2016, sobre la primera declaración del estado de alarma desde la entrada en vigor de la CE, se limita a afirmar, aunque de pasada, que suspensión es algo distinto a limitación de derechos, pero sin aclarar en qué se diferencian ambos conceptos; como se demuestra en el análisis del caso, no resulta relevante qué estado excepcional se proclame, pues el principio de proporcionalidad debe respetarse siempre: C. VIDAL PRADO y D. DELGADO RAMOS (2011), «Algunas consideraciones sobre la declaración del estado de alarma y su prórroga», Revista Española de Derecho Constitucional, n ${ }^{\circ}$ 92, esp. pp. 253-260. Sea como fuere, creo que debería construirse un concepto único de suspensión de derechos, válido tanto para la suspensión general como para la individual: así, P. CRUZ VILLALÓN (1984), Estados excepcionales y suspensión de garantías, Madrid, Tecnos, pp. 155-157, y con más argumentos, G. MAESTRO BUELGA y A. LÓPEZ BASAGUREN (1988), «Garantismo, emergencia y suspensión de derechos fundamentales en la legislación de excepción», Revista Vasca de Administración Pública, no 21, pp. 25-30. Como bien apunta E. VÍRGALA FORURIA (1994), «La suspensión de derechos por terrorismo en el ordenamiento español», Revista Española de Derecho Constitucional, $\mathrm{n}^{\circ} 40$, pp. 66-67, al menos sabemos que nos encontramos ante un concepto distinto al de "pérdida de derechos fundamentales» de la Constitución alemana, que no existe en nuestro Derecho. 
la necesidad de resolver casos concretos, la construcción de conceptos ${ }^{7}$ : se equivocan quienes pretenden buscar en las sentencias las definiciones que competen a los académicos.

En cuanto a la doctrina, interesa destacar de entrada, y sin ánimo exhaustivo, las aportaciones más relevantes ${ }^{8}$. En un trabajo de 2001, la profesora Paloma REQUEJO afirma que «suspensión» no equivale a «desaparición» ni a «supresión» de los dere$\operatorname{chos}^{9}$, y que en estos casos debe respetarse el principio de proporcionalidad, pero no el contenido esencial (volveré sobre ello al final), aunque sí «el mínimo indispensable que le permite conservar su naturaleza de derecho fundamental», que viene a ser lo mismo. Añade que «Mientras dura la excepcionalidad se permite una intervención de los poderes públicos de mayor calado, por lo que las garantías que de ordinario disfruta el derecho sufren una «rebaja» considerable, si bien su titular puede seguir exigiendo, como en cualquier otra circunstancia, que la injerencia se produzca en los términos que normativamente se establezca». Si bien la autora no define con claridad el concepto, me interesa sobre todo conocer la justificación que ofrece de su, más bien negativo (lo que no es suspensión), apunte de definición; aunque no es fácil encontrarlo, parece hallarse en un valor previo, diríamos meta-jurídico, la legitimidad, entremezclado con razones pragmáticas:

Si el objetivo último del derecho de excepción no solo es superar la situación de emergencia, sino también restablecer la vigencia de la normalidad constitucional, tanto más fácil será, cuanto mayor fidelidad se guarde durante el período de excepción a lo que la Constitución era y pretende seguir siendo. La vuelta condiciona el alcance del «sacrificio» constitucional en que consiste la terapia. Si el remedio no quiere ser peor que la enfermedad, para que la Constitución se imponga de nuevo no puede perder un ápice de legitimidad, propugnando medidas irrazonables y desproporcionadas que hagan irreconocibles sus principios estructurales.

7 De interés, p. ej., R. A. POSNER (2011), «Los jueces no son profesores de Derecho», en Cómo deciden los jueces, Madrid, Marcial Pons, pp. 229 y ss. La referencia es significativa, procediendo de un país donde la academia practica más el case law que nosotros.

8 La bibliografía sobre el art. 55 CE es ya numerosa, pero raramente la doctrina se detiene a definir el concepto «suspensión de derechos»; para una selección de esta bibliografía me remito al comentario al precepto de P. REQUEJO RODRÍGUEZ (2018), en M. Rodríguez-Piñero y M. E. Casas (dirs.), Comentarios a la Constitución española, Madrid, Wolters Kluwer, pp. 1.521 y ss. Hasta donde conozco, la última aportación al tema en las revistas académicas españolas es la de P. FERNÁNDEZ DE CASADEVANTE (2020), «El derecho de emergencia constitucional en España: hacia una nueva taxonomía», Revista de Derecho Político, $\mathrm{n}^{\circ} 7$, pero tampoco encontramos en ella una definición de «suspensión de derechos». En cuanto al comentario al art. 55 de F. FERNÁNDEZ SEGADO en la segunda edición de los ya clásicos Comentarios a la Constitución española de 1978 dirigidos por O. Alzaga Villaamil (Madrid, Edersa, 1996, tomo IV, pp. 583 y ss.), aunque tampoco presenta una definición clara, adelanta una determinación negativa del concepto: «en modo alguno puede admitirse que la suspensión de derechos, motivada por una situación de emergencia, pueda suponer la derogación, inexistencia o aun desconocimiento, ni tan siquiera con carácter temporal, de un o unos determinados derechos fundamentales» (p. 590). En 1996 casi nadie hablaba todavía del principio de proporcionalidad.

9 P. REQUEJO RODRÍGUEZ. (2001), «¿Suspensión o supresión de derechos fundamentales?», Revista de Derecho Político, n 51, pp. 110-113. 
Este modo de razonar, apuntado años antes por uno de nuestros primeros especialistas en el tema ${ }^{10}$, me parece correcto: un concepto aparentemente técnico resulta en realidad valorativo y puede concretarse de diversas maneras, debiendo optarse por la definición más coherente con el valor que previamente se defiende, en este caso la legitimidad ${ }^{11}$. Si el valor a defender hubiera sido, por ejemplo, la seguridad, con bastante probabilidad se habría llegado a una definición diferente ${ }^{12}$.

Poco después, el también profesor de la Universidad de Oviedo, Benito ALÁEZ, vuelve sobre el tema en un trabajo titulado precisamente «el concepto de suspensión general de los derechos fundamentales» ${ }^{13}$. De entrada, ALÁEZ reduce a dos las posibilidades de definir el concepto de suspensión: o «auténtica suspensión» o «forma más o menos intensa de limitación», que parecen corresponderse, respectivamente con dos modelos, «desconstitucionalización» (como si el derecho «no estuviese protegido por una norma iusfundamental, puesto que la misma ha perdido temporalmente su vigencia» ${ }^{14}$ ) y «desfundamentalización» (no se respeta el contenido esencial

10 P. CRUZ VILLALÓN (1984), Estados..., cit., pp. 22-23.

11 Un planteamiento similar, en F. FERNÁNDEZ SEGADO, op. y loc. cit., esta vez con apoyo indirecto en FRIEDRICH. Por su parte, en un trabajo interesante pero más bien centrado en el art. 55.2, J. ACOSTA SÁNCHEZ (2008), «Suspensión de derechos y libertades», en M. Jiménez de Parga y F. Vallespín (eds.), España siglo xxI: la política, Madrid, Biblioteca Nueva, pp. 387-388, apunta bien la cuestión metodológica (demostrando implícitamente, por cierto, la inconveniencia de interpretar la Constitución desde la Historia), cuando sostiene que la construcción de este concepto depende a su vez del concepto (concepción diría yo) de Constitución que se adopte como presupuesto.

12 No nos engañemos: nuestra concepción teórica previa, explícita o no, condiciona nuestra formulación de conceptos, que raramente es inocente o neutral. En un importante trabajo de 2017, el politólogo W. E. SCHEUERMAN («Human rights lawyers v. Carl Schmitt», en E. J. Criddle (ed.), Human Rights in Emergencies, Cambridge, Cambridge University Press, pp. 175 y ss.) describe tres modelos posibles: el legalismo internacional (defendido por FITZPATRICK, que confía ingenuamente en las posibilidades del Derecho internacional), el enfoque extralegal (que sostienen GROSS y AOLÁIN, demasiado realista y poco garantista, y que vendría a coincidir, en mi opinión, con el sostenido por la mayoría de nuestra doctrina, como enseguida veremos), y la concepción de los derechos humanos como deberes fiduciarios, que ejemplifica en los escritos de CRIDDLE y FOX-DECENT. En este último modelo se inscribe este trabajo, que parte de una concepción fuerte de los derechos humanos, apostando por una interpretación de los mismos conforme a valores y coherente con los principios constitucionales: el Derecho de excepción no es tan excepcional pues la esencia de los derechos nunca se pierde.

13 B. ALÁEZ CORRAL (2004), «El concepto de suspensión general de los derechos fundamentales», en La defensa del Estado, Valencia, Tirant lo Blanch, esp. pp. 233-236 y 241-244.

14 Esta idea recuerda a un oscuro pasaje de H. KELSEN (Teoría pura del Derecho, UNAM, México, 1998 , p. 245) donde el máximo representante del positivismo jurídico parece admitir que una Constitución pueda designar un órgano de decisión habilitado para dictar normas contrarias a la propia Constitución, pero como hace tiempo demostró E. BULYGIN ( Cognition and interpretation of law», en L. Gianformaggio y S. Paulson (eds.), Cognition and interpretation of law, Turin, Giapichelli, 1995), esto contradice el principio de jerarquía del propio Kelsen, y se acerca peligrosamente (añado) al decisionismo de Carl Schmitt. La idea de «desconstitucionalización» viene a coincidir con el modelo «suspensión como legalización» (p. ej., T. W. MORRISON (2007), «Suspension and the extrajudicial Constitution», Columbia Law Review, $\mathrm{n}^{\circ}$ 107, esp. pp. 1.533-1.539), minoritario incluso en Estados Unidos (apenas lo defiende D. L. SHAPIRO (2006), «Habeas Corpus, suspension, and detention: another view», Notre Dame Law Review, n 59, esp. pp. 86-89), y justamente criticado como «un agujero negro 
pero sí el principio de proporcionalidad ${ }^{15}$ ). Tras un breve paréntesis sobre el sentido de la regulación de los estados excepcionales («el propio texto constitucional trata de autoprotegerse»), del que no se extraen consecuencias, y después de un repaso por los modelos del Derecho comparado, se concluye por fin con una definición:

La suspensión a que hace referencia el art. 55.1 CE ha de ser entendida en un sentido estricto, y además formal, como la temporal supresión de la vigencia de las normas constitucionales sobre determinados derechos fundamentales, y no como una mera limitación suspensiva de los mismos. [...] La suspensión conlleva, por tanto, la desconstitucionalización de la norma iusfundamental, $[\ldots$ lo que $]$ tiene como consecuencia que únicamente cabrá tachar de inconstitucional la actuación del legislador que sea no razonable.

El argumento de apoyo a esta definición, exclusivamente hispánica, del concepto de suspensión, no está claro, pero parece ser el tenor literal de la propia Constitución. El argumento podría reconstruirse así:

1. Solo caben dos modelos de suspensión: supresión (desconstitucionalización) o limitación intensa (desfundamentalización).

2. En España la regulación constitucional de los estados excepcionales es muy restrictiva y rígida.

3. Luego, España sigue el primer modelo (desconstitucionalización).

Pues bien, ni me convence la premisa dualista de partida (que es una petición conceptual de principio) ni me convence el argumento según el cual «cuanto más regulación, menos derechos», pues no creo que de lo primero se derive sin más lo segundo ${ }^{16}$ sino en todo caso lo contrario, como más adelante intentaré demostrar.

jurídico»: por todos, D. DYZENHAUS (2006), «Schmitt v Dicey: are states of emergency inside or outside the legal order?», Cardozo Law Review, n 27. En Francia, M. TROPER (2017), «El estado de excepción no tiene nada de excepcional», Revista de Derecho constitucional europeo, $\mathrm{n}^{\circ} 27$, pretende salvar el problema afirmando que el Derecho siempre existe, aunque se encuentre implícito, pero su planteamiento formalista no soluciona el problema de fondo, y que depende de la concepción del constitucionalismo que se mantenga. Normalmente, en los países con Derecho constitucional de excepción expreso, los derechos están mejor protegidos; al final de este trabajo volveré sobre esta idea.

15 Parecería que en este segundo modelo los derechos fundamentales quedaran «degradados» a meros derechos subjetivos, esto es, no resistentes al poder legislativo. Puedo aceptar (después volveré sobre ello) que, como consecuencia de la aparición de límites más amplios, los derechos sufren, pero no tanto en su contenido (como tempranamente vino a proponer T. DE LA QUADRA-SALCEDO (1983), «La naturaleza de los derechos fundamentales en situaciones de suspensión», Anuario de Derechos Humanos, $\mathrm{n}^{\mathrm{o}} 2$, p. 458-462, trabajo por cierto que sigue siendo útil y donde ya se apunta la necesidad de interpretación conforme al CEDH, llegándose en el fondo a conclusiones no muy distintas a las que aquí se van a mantener) como en su efectividad en la práctica. En todo caso, no creo discutible que siguen siendo exigibles ante los tribunales; de interés, por todos, C. GARRIDO LÓPEZ (2017), «Naturaleza jurídica y control jurisdiccional de las decisiones constitucionales de excepción», Revista Española de Derecho Constitucional, $\mathrm{n}^{\circ} 110$, pp. 50 y ss.

16 Posiblemente, la tesis de ALÁEZ haya influido en que la propia REQUEJO modifique después su postura: en un trabajo publicado el mismo año (2004), «La suspensión de los derechos fundamentales», en F. J. Bastida Freijedo y otros, Teoría general de los derechos fundamentales en la Constitución española de 1978, Madrid, Tecnos, p. 223, afirmará: «Nuestra Constitución permite una suspensión, y no una mera 
Hasta aquí las principales aportaciones doctrinales, que precisamente por dejarme algo insatisfecho, me motivan a escribir este artículo, que parte de un replanteamiento metodológico. A mi juicio, debemos intentar un diálogo científico internacional, al menos entre los Estados constitucionales, con miras a la construcción de un cierto Derecho común de los derechos humanos y fundamentales; dada la gran heterogeneidad de las legislaciones nacionales en la materia ${ }^{17}$, la única base firme para ello es el Derecho internacional ${ }^{18}$. Los conceptos «derechos humanos»y «derechos fundamentales» son conceptos próximos, y cada vez más, pero no idénticos ${ }^{19}$. Una de las formas de conexión entre ambos, que sirve tanto para la dogmática, en su tarea de interpretación del Derecho vigente, como para la teoría, en su labor de construcción de un Derecho común, consiste en proponer conceptos que sirvan tanto a los derechos humanos como a los derechos fundamentales. En lo sucesivo, intentaré demostrar que resulta posible (y necesario) un concepto de suspensión de derechos bumanos y fundamentales presidido por la óptica de los primeros; en otras palabras, que el Derecho internacional ofrece pautas suficientes para definir en términos «internacionalmente adecuados» ${ }^{20}$ el concepto de suspensión de derechos fundamentales.

limitación, de los derechos fundamentales, es decir, una supresión temporal de la vigencia de la norma constitucional que los acoge».

17 Para la panorámica europea, V. FAGGIANI (2012), «Los estados de excepción. Perspectivas desde el Derecho constitucional europeo», Revista de Derecho Constitucional Europeo, $\mathrm{n}^{\circ}$ 17. Para América Latina, FEDERACIÓN IBEROAMERICANA DEL OMBUDSMAN (2021), XVIII Informe sobre derechos humanos: estados excepcionales y COVID-19, Madrid, Defensor del Pueblo.

18 Como es bien conocido, desde la teoría de la interpretación (que es solo una parte de la teoría), ya hace años P. HÄBERLE propuso un «quinto método de interpretación», el recurso al Derecho comparado, pero resulta todavía más útil el Derecho internacional, pues este sí es realmente "común». En un interesante trabajo, S. LEGARRE y C. ORREGO (2010), «Los usos del Derecho comparado y la universalidad de los derechos humanos», Revista Española de Derecho Constitucional, no 88, esp. pp. 23 y ss., adoptan un enfoque algo diferente, más iusnaturalista que internacionalista, pero en todo caso no incompatible con el que aquí se propone.

19 Sobre las diferencias y conexiones entre ambos, últimamente, p. ej., G. ESCOBAR ROCA (2018), Nuevos derechos y garantías de los derechos, Madrid, Marcial Pons, pp. 24-32.

20 En nuestro Derecho se trata además de una obligación del intérprete (art. 10.2 CE). Resulta significativo que en ordenamientos que carecen de una cláusula de este tipo, como el alemán, se llegue a una conclusión semejante, aunque lógicamente acentuándose menos su componente obligacional. Las resistencias son comprensibles, pues a ningún Tribunal Constitucional le gusta auto-limitarse, y de hecho el nuestro nunca ha aceptado su vinculación a la jurisprudencia de Estrasburgo, léase la obligación de interpretar los derechos de la $\mathrm{CE}$ según el $\mathrm{CEDH}$, lo que en algún caso puede justificarse (argumentando p. ej. que un derecho del CEDH carece de equivalente en la CE o que determinada interpretación del CEDH resulta incompatible la CE: no son estos los casos, como intentaré demostrar, de la materia objeto de este estudio). En la doctrina española, en su comentario al art. 55, ya citado, donde por cierto mantiene su segunda tesis sobre el concepto de suspensión (la de 2004, no la de 2001), REQUEJO apunta el método (p. 1.539) pero luego no extrae de la doctrina del TEDH ninguna consecuencia para la interpretación de la CE; lo mismo sucede en el ya citado artículo de FAGGIANI. El único trabajo dedicado a conectar en este punto el CEDH y la CE creo que es el de M. J. ROCA (2019), «La suspensión del Convenio Europeo de Derechos Humanos desde el Derecho español: 


\section{CONSEJO DE EUROPA}

\subsection{El Convenio Europeo de Derechos Humanos en la interpretación del Tribunal de Estrasburgo}

En términos cronológicos, la primera regulación internacional de los estados excepcionales $^{21}$, aparte el Derecho de guerra, se encuentra en el Convenio Europeo de Derechos Humanos de $1950^{22}$ (CEDH). Según su artículo 15, denominado «Derogación en caso de estado de urgencia» ${ }^{23}$ :

1. En caso de guerra o de otro peligro público que amenace la vida de la nación, cualquier Alta Parte Contratante podrá tomar medidas que deroguen las obligaciones previstas en el presente Convenio en la estricta medida en que lo exija la situación, y a condición de que tales medidas no estén en contradicción con las restantes obligaciones que dimanan del derecho internacional.

2. La disposición precedente no autoriza ninguna derogación del artículo 2, salvo para el caso de muertes resultantes de actos lícitos de guerra, ni de los artículos 3, 4 (párrafo 1) y 7 .

3. Toda Alta Parte Contratante que ejerza este derecho de derogación tendrá plenamente informado al Secretario General del Consejo de Europa de las medidas tomadas y de los motivos que las han inspirado. Deberá igualmente informar al Secretario General del Consejo de Europa de la fecha en que esas medidas hayan dejado de estar en vigor y las disposiciones del Convenio vuelvan a tener plena aplicación.

La traducción española del inglés derogation y del francés dérogation es literal, con un pequeño matiz diferenciador de ambas versiones ${ }^{24}$. La inicial interpretación lite-

procedimiento y control», Revista Española de Derecho Europeo, $\mathrm{n}^{\circ} 72$, pero se limita a los aspectos formales, sin entrar en el tema que aquí interesa, que es el concepto de suspensión.

21 En 1949 se produjo en las Naciones Unidas un intento fallido de aprobar un convenio internacional de derechos humanos, donde figuraba un precepto similar al poco después aprobado por el Consejo de Europa.

22 Formaban entonces parte del Consejo de Europa trece países: como Estados fundadores en 1949, Bélgica, Dinamarca, Francia, Holanda, Irlanda, Italia, Luxemburgo, Noruega, Reino Unido y Suecia, incorporándose poco después Grecia, Turquía y la República Federal de Alemania. En pocas de las Constituciones entonces vigentes en esos países se hacía mención expresa a la suspensión de derechos y al parecer el precepto tuvo su origen en la insistencia del Reino Unido (con las reticencias de Francia e Italia), quizás ya entonces preocupado por la creciente implantación del IRA, que efectivamente inició sus ataques terroristas en 1950. Los trabajos preparatorios del art. 15 pueden consultarse en https://www. echr.coe.int/LibraryDocs/Travaux/ECHRTravaux-ART15-DH(56)4-EN1675477.pdf y en CONSEJO DE EUROPA (1976), Collected edition of the travaux préparatoires of the European Convention on Human Rights, La Haya, Martinus Nijhoff.

23 La traducción oficial española del título del precepto se asemeja más al original francés (dérogation en cas d'état d'urgence) que al inglés (derogation in time of emergency), y parece denotar una cierta obligatoriedad de la declaración formal de la emergencia; más adelante se verá que no ha sido exactamente así.

24 El art. 15 parece aludir a la suspensión de los arts. 57 y 58 de la Convención de Viena sobre el Derecho de los Tratados, de 1969, de ahí que la misma doctrina internacionalista critique el término 
$\mathrm{ral}^{25}$ apunta a una desaparición (temporal, en todo caso) de las obligaciones de Derecho internacional, pero esto es solo aparente: la mención al mantenimiento «de las restantes obligaciones que dimanan del derecho internacional» resulta al respecto especialmente significativa. Habría sido más correcto, en todo caso, traducir el término como «suspensión» (curiosamente, así se hace en la versión oficial en castellano del PIDCP, que utiliza el mismo término, derogation), y así creo que debe leerse hoy el Convenio, aunque solo sea para facilitar el necesario diálogo entre Derecho internacional y constitucional.

Aunque ello implique comenzar por el apartado final del precepto, la jurisprudencia apenas ha extraído consecuencias prácticas de la declaración formal del estado de emergencia y de su posterior notificación al Consejo de Europa ${ }^{26}$. En el momento de cierre de este trabajo, con motivo de la pandemia del COVID-19 diez Estados parte del CEDH habían informado sobre la declaración del estado de emergencia en su país al Secretario General del Consejo de Europa ${ }^{27}$, lo que indica que los Estados parte parecen sentirse vinculados por una suerte de obligación de declaración, y consiguientemente, de notificación ${ }^{28}$.

El supuesto de hecho para la suspensión es doble: uno muy concreto, y aun así relativamente (la guerra ${ }^{29}$ ) y otro bastante ambiguo, «peligro público que amenace la vida de la nación». Se trata de una previsión de futuro, y parece lógico que exista aquí un amplio margen de apreciación nacional, por encontrarse las autoridades

«derogación», cuando lo correcto habría sido «suspensión»; p. ej., P. A. FERNÁNDEZ SÁNCHEZ (2014), «La suspensión de las garantías establecidas en el Convenio Europeo de Derechos Humanos (art. 15)», en J. García Roca y P. Santolaya (coords.), La Europa de los derechos, Madrid, CEPC, pp. 613-614.

25 Que no será la seguida en este trabajo; sobre su inconveniencia, al menos como criterio único en materia de derechos fundamentales, resulta interesante el FJ 8 de la STC 198/2012, sobre el matrimonio homosexual.

26 Una relativa excepción es Braningan y Mac Bride contra Reino Unido, de 26 de mayo de 1993, § 73 , pero el argumento es por remisión al PIDCP (que se encuentra entre las «demás obligaciones que dimanan del Derecho internacional», citadas en el art. 15.1), que después se citará.

27 Se trata de Albania, Armenia, Estonia, Georgia, Letonia, Macedonia del Norte, Moldavia, Rumanía, San Marino y Serbia: https://www.coe.int/en/web/conventions/full-list/-/conventions/ treaty/005/declarations?p_auth $=$ oC00wpDOm, consultada el 11 de mayo de 2020.

${ }_{28}$ Para más detalles sobre estas obligaciones formales, en las que no podemos detenernos, I. LAZKANO BROTÓNS e I. LASAGABASTER HERRARTE (2015): «Artículo 15. Derogación en caso de estado de urgencia», en I. Lasagabaster Herrarte (dir.), Convenio Europeo de Derechos Humanos. Comentario sistemático, Cizur Menor, Civitas, $3^{a}$ ed., pp. 805-808.

29 El concepto de guerra resulta jurídicamente ambiguo, incluso en Derecho internacional, y hoy parece poco frecuente la declaración formal, hablándose más bien de «conflictos armados». Sin embargo, no son lo mismo; p. ej., España intervino en la guerra de Irak, y no por ello puede afirmarse que España estuviera «en guerra». Tampoco creo que en esa circunstancia se estuviera en presencia de un peligro público que amenazara la vida de la nación española. El concepto de guerra no ha sido definido tampoco por el TEDH, pero este ya ha advertido que las obligaciones internacionales no pierden su vigencia cuando el Estado actúa militarmente fuera de su territorio (Hassan contra Reino Unido, de 16 de septiembre de 2014, § 101). 
nacionales mejor equipadas para verificar la existencia de dicho peligro ${ }^{30}$; en términos de teoría de los derechos, el «peligro público» es el límite genérico (que en todo caso deberá concretarse en otro más específico, como p. ej. la lucha contra el terrorismo) de los mismos, e incluso a nivel interno existe una amplia discrecionalidad al respecto $^{31}$. Como vamos a comprobar, el Tribunal Europeo de Derechos humanos (en adelante, TEDH o Estrasburgo) no presta demasiada atención al supuesto de hecho, y se centra más bien en la proporcionalidad entre el límite y los derechos afectados.

La regla general, a diferencia del Derecho constitucional, es que todos los derechos se pueden suspender. Parece claro que el Convenio queda aquí algo anticuado, en contraste con documentos posteriores, como después se verá. Las excepciones son solo cuatro: el derecho a la vida (con la excepción, a su vez, de las muertes resultantes de actos lícitos de guerra), el derecho a no sufrir torturas ni penas y tratos inhumanos o degradantes, el derecho a no sufrir esclavitud o servidumbre y el derecho a la legalidad penal. El catálogo de derechos que no pueden ser suspendidos resulta sin duda escueto pero indirectamente nos ofrece una pista importante: suspensión y restricción son conceptos distintos pero muy próximos. Veamos: en los estados excepcionales la vida (dejemos fuera la guerra, pues parece un supuesto casi de laboratorio) no se puede suspender pero sí restringir; sin embargo, los derechos a no sufrir esclavitud o servidumbre ${ }^{32}$ o torturas o penas y tratos inhumanos o degradantes no se pueden suspender ni restringir, en una suerte de coincidencia entre contenido del derecho y contenido esencial. En cuanto a la legalidad penal, el contenido del derecho es bastante flexible, pero una vez dentro de él, no admite excepciones.

Lo más relevante del artículo 15, a efectos del Derecho constitucional, es el inciso «en la estricta medida en que lo exija la situación», que no figura en el artículo 55.1

30 Véase no obstante la crítica de O. GROSS y F. NÍ AOLAIN, F. (2001), «From discretion to scrutiny: revisiting the application of the margin of appretiation doctrine in the context of article 15 of the European Convention on Human Rights», Human Rights Quarterly, n 23, esp. pp. 637-649, defendiendo con buenos argumentos un recorte sustancial de este margen de apreciación, sobre todo para los estados excepcionales prolongados. Para esta y otras críticas, véase la nota 47.

31 Si los derechos fundamentales son normas constitucionales, parecería lógico que sus límites fueran también normas constitucionales, y así lo afirmó en un comienzo nuestra doctrina. Sin embargo, el Tribunal Constitucional admite con frecuencia límites de los derechos fundamentales no previstos en la Constitución, bastándole con que sean legítimos; quizás por ello, las últimas aportaciones no tienen más remedio que hacer una concesión al realismo y admitirlo así (p. ej., M. GONZÁLEZ BEILFUSS (2015), El principio de proporcionalidad en la jurisprudencia del Tribunal Constitucional, Cizur Menor, Aranzadi, p. 100).

32 Sobre el art. 4.1 la jurisprudencia es escasa y el TEDH suele reconducir los casos de obligaciones de trabajar a los demás apartados del precepto. En las pocas ocasiones en que se utiliza directamente el art. 4.1, queda claro que su contenido es absoluto, esto es, que no admite restricción alguna (p. ej., Silidian contra Francia, de 26 de julio de 2005). En cuanto a los casos de trata de personas, suele citarse genéricamente el art. 4 (aunque a veces específicamente el 4.2), y en esas sentencias queda claro también que se trata de un derecho absoluto. 
$\mathrm{CE}^{33}$, de ahí su utilidad. Pues bien, a partir de él, el TEDH ha considerado aplicable el principio de proporcionalidad a los estados excepcionales. Interesa describir brevemente esta doctrina, trascendental para el objetivo de este estudio, centrándonos en las sentencias más relevantes ${ }^{34}$ y en su utilidad para la construcción conceptual que aquí se pretende.

El primer caso relevante ${ }^{35}$ es Lawless contra Irlanda, de 1 de julio de 1961, sobre las medidas contra el terrorismo del IRA. El 5 de julio de 1957 Irlanda había decretado el estado de excepción, y así lo notificó al Consejo de Europa mediante carta de 20 de julio, aceptando el TEDH que se producía el supuesto de hecho de aplicación del artículo $15 \mathrm{CEDH}^{36}$ y que las medidas adoptadas resultaban en principio adecuadas a la consecución del objetivo genérico de evitar la «amenaza para la vida de la nación» y al específico de combatir eficazmente el terrorismo. Sin embargo, el Tribunal no se queda ahí, pues analiza la proporcionalidad de la medida adoptada contra el demandante, en concreto su detención durante cinco meses en un campo militar sin autorización judicial. El uso del principio de proporcionalidad es todavía muy

33 Aunque sí en el art. 1.2 de la LO 4/1981: «Las medidas a adoptar en los estados de alarma, excepción y sitio, así como la duración de los mismos, serán en cualquier caso las estrictamente indispensables para asegurar el restablecimiento de la normalidad. Su aplicación se realizará en forma proporcionada a las circunstancias».

34 En la búsqueda en la base de datos oficial del TEDH (HUDOC) por sentencias de fondo sobre el art. 15, realizada el 20 de mayo de 2020, aparecen 24 resultados, pero en varios de ellos el precepto se cita de pasada, sin trascendencia para el fallo. El propio Consejo de Europa ha publicado recientemente una Guide on article 15 of the Convention, actualizada a 31 de diciembre de 2019, que es una útil síntesis sistemática de la doctrina del TEDH. En cuanto a los estudios incluidos en los dos grandes comentarios en castellano al CEDH, ya citados, apenas se ocupan de la cuestión que aquí más nos interesa, la búsqueda de criterios de interpretación del art. 55 CE. Por mi parte, prefiero seguir aquí una exposición cronológica y no sistemática, para verificar la evolución jurisprudencial y atender mejor al contexto de cada sentencia, pues esta materia es muy casuística; de interés, E. CRIDDLE (2014), «Protecting human rights during emergencies: delegation, derogation and deference», Netherlands Yearbook of International Law, $\mathrm{n}^{\circ}$ 45. Previamente a este trabajo, en castellano puede verse J. C. REMOTTI CARBONELL (1997), «El derecho de derogación en la jurisprudencia del Tribunal Europeo de Derechos Humanos: criterios generales», en Y. Gómez Sánchez (coord.), Los derechos en Europa, Madrid, UNED.

35 La extinta Comisión de Derechos Humanos se pronunció después (el caso no llegó al TEDH) sobre el golpe de Estado de los coroneles en Grecia de 1967, considerando que no se daba el supuesto de hecho de aplicación del art. 15, y llegando incluso a proponer la salida de Grecia del Consejo de Europa, lo que efectivamente se produjo; véase el Report of the European Commission of Human Rights on the «Greek case», de 5 de noviembre de 1969.

36 Para el TEDH, la existencia en ese momento de una «emergencia pública que amenaza la vida de la nación» fue deducida razonablemente por el Gobierno irlandés de una conjunción de factores: la existencia de un ejército secreto dedicado a actividades anticonstitucionales y que empleaba la violencia para alcanzar sus propósitos; que este ejército estaba operando fuera del territorio irlandés y, por consiguiente, comprometiendo gravemente las relaciones de vecindad de la República; y el crecimiento progresivo y alarmante de las actividades terroristas desde el otoño de 1956 y, muy especialmente, en la primera mitad de 1957. 
$\operatorname{tosco}^{37}$, pero lo que importa es resaltar su mera utilización, es decir, aunque la libertad personal puede formalmente ser «suspendida», esta no desaparece, no se «deroga» propiamente.

El mismo fenómeno terrorista reaparece diecisiete años después, esta vez con Irlanda demandando al Reino Unido por su supuesto exceso en su lucha contra el IRA. En Irlanda contra Reino Unido, de 18 de enero de 1978, el razonamiento es diferente en relación con los derechos «inderogables» y con los «derogables». La tortura y los malos tratos nunca pueden justificarse; tras constatarse su evidencia, y calificar como malos tratos algunas de las técnicas $\left(\right.$ no todas ${ }^{38}$ ) de interrogatorio utilizadas por el ejército británico, el Tribunal declara (por vez primera en situaciones excepcionales) la violación del artículo 3. En cuanto a los derechos «derogables», se formula explícitamente, también por vez primera en la historia del Tribunal, el concepto de «margen de apreciación nacional» ${ }^{39}$; en el caso, a la hora de apreciar la existencia del supuesto de hecho del artículo 15.1. Por lo que se refiere a las restricciones a la libertad personal y a las garantías judiciales, se analiza su proporcionalidad, pero de forma muy somera, llegándose, como en Lawless, a la conclusión de que fueron necesarias para la consecución del objetivo perseguido. Una forma similar de argumentación puede verse en Brogan y otros contra Reino Unido, de 29 de noviembre de 1988.

Cinco años más tarde, en Brannigan y McBride contra Reino Unido, de 26 de mayo de 1993, el principio de proporcionalidad comienza a refinarse. Se analiza nuevamente aquí la adecuación al Convenio de las restricciones a la libertad personal, y esta vez la argumentación es más detallada; en síntesis, sus razonamientos se centraron en dos cuestiones:

a) Si la falta de revisión judicial de la custodia policial prolongada estaba justificada. De acuerdo con diversos informes sobre la aplicación de la legislación contra el terrorismo, las dificultades inherentes a la investigación y el enjuiciamiento de estos delitos exigían una extensión del período de custodia policial sin control judicial. El gobierno consideraba esencial evitar que el detenido y su abogado conocieran determinados datos; de otro lado, aplican-

37 Para el TEDH, «no hay nada que pruebe que los poderes de detención conferidos al Gobierno irlandés por la ley [...] fuesen empleados contra el demandante [...] con una finalidad distinta a la prevista [o] que fuera más allá de las exigencias de la situación en ese momento». Además, el Tribunal tiene en cuenta que la asociación de Lawless con el IRA estaba demostrada, y que el gobierno le ofreció su liberación si se comprometía a cumplir la ley, y que Lawless finalmente lo aceptó, siendo puesto en libertad inmediatamente.

38 Advirtamos, de pasada, una tesis implícita pero importante: al menos una parte del contenido del derecho a la integridad es contenido esencial en un sentido absoluto, es decir, nunca puede ser restringido; véase más adelante la nota 70.

39 Figura como el primer ámbito «natural» de aplicación de la tan traída y llevada doctrina del margen de apreciación (en la que no puedo entrar ahora), según F. TULKEN y L. DONNAY (2006), «L'usage de la marge d'appreciation par la Cour européenne des droits de l'homme. Pravent juridique superfluo u mécanisme indispensable par nature», Revue de Science Criminnelle et de Droit Pénal Comparé, $\mathrm{n}^{\circ} 1$, p. 6. 
do el Derecho ordinario, la independencia del poder judicial se habría visto comprometida si los jueces hubieran participado en tales decisiones. Para Estrasburgo, bien pueden interpretarse los apartados 4 y 5 del artículo 5 en el sentido de que la intervención del juez puede variar según el tipo de proceso. En cuanto a la naturaleza de los medios más adecuados para enfrentar la crisis, el Tribunal aceptó la posición del gobierno, directamente responsable de lograr un equilibrio entre las medidas efectivas para combatir el terrorismo y el respeto de los derechos individuales. No puede decirse, a juicio del TEDH, que el gobierno se excediera en su margen de apreciación al excluir la revisión judicial en las circunstancias excepcionales que vivía el país.

b) Si las garantías contra los posibles abusos fueron suficientes. Al respecto, el Tribunal consideró que las garantías legales brindaron una protección efectiva contra un eventual comportamiento arbitrario de las autoridades. En primer lugar, el recurso al habeas corpus (que estuvo a disposición de los demandantes y de sus abogados desde las 48 horas posteriores a la detención) permitió una revisión de la legalidad de la detención. Tampoco se impidió a los detenidos informar a un pariente o amigo de su detención ni que un médico les examinara. De otro lado, expertos independientes examinaron, a intervalos regulares, el funcionamiento de la legislación aplicable, que fue modificada en varias ocasiones. Por todo ello, el TEDH concluyó que, teniendo en cuenta la naturaleza de la amenaza terrorista en Irlanda del Norte, el alcance limitado de la excepción y los motivos invocados en apoyo de la misma, así como la presencia de garantías contra el abuso, el Reino Unido no vulneró el artículo $5^{40}$. Existen sin embargo cuatro votos disidentes, que postulan un uso más estricto del principio de proporcionalidad, que efectivamente irá llegando paulatinamente.

La doctrina de Estrasburgo continúa evolucionando hacia un control más riguroso, advirtiéndose un cierto giro en la primera serie de casos sobre Turquía (19962006), sobre la lucha contra el terrorismo en el país. En Aksoy contra Turquía, de 18 de diciembre de 1996, también centrada en la libertad personal durante la vigencia de estados excepcionales, se comienza con la cita de Brogan, pero esta vez el escrutinio es más estricto ${ }^{41}$ : un período prolongado de custodia policial sin revisión judicial (catorce días en el caso) va más allá de lo razonable y resulta contrario al artículo 5. Ante el alegato del gobierno turco de la excepción del artículo 15, el Tribunal responde que, pese al margen de apreciación nacional propio de estos casos, «los Estados no disfrutan de un poder ilimitado en este área» y el Tribunal está «obligado a atri-

40 El último episodio de la saga sobre el IRA es la Decisión (no Sentencia) Marshall contra Reino Unido, de 10 de julio de 2001, que inadmite a trámite la demanda, y reitera este planteamiento.

41 Suele afirmarse que el TEDH utiliza un doble rasero para los países del este y del oeste de Europa, pero no hay pruebas de ello en este campo: luego veremos que el Reino Unido pronto será «condenado», y después Ucrania «absuelta». 
buir el peso apropiado a factores relevantes como la naturaleza de los derechos afectados por la suspensión, la duración del estado de emergencia y las circunstancias que lo crearon». La amenaza para la vida de la nación provocada por la actividad terrorista del PKK en el sureste de Turquía era real. Sin embargo, el Tribunal no aceptó que fuera necesario detener a un sospechoso durante catorce días sin intervención judicial: este período excepcionalmente largo dejó al demandante a merced no solo de violaciones arbitrarias de su derecho a la libertad, sino también de tortura; además, el Gobierno no justificó con razones detalladas por qué la lucha contra el terrorismo hacía impracticable cualquier intervención judicial. En estas circunstancias, a pesar de la gravedad de la amenaza terrorista y de la invocación del artículo 15, Estrasburgo concluyó que Turquía no respetó el principio de proporcionalidad, vulnerando así el artículo 5.3 CEDH. En las sentencias posteriores sobre Turquía ${ }^{42}$, todas ellas estimatorias y concluyendo igualmente la violación del artículo 5, se insiste en la misma dirección, pero resulta especialmente significativo que, pese a la declaración y notificación del estado de excepción, apenas se haga ya mención al artículo 15, como si el concepto de suspensión de derechos hubiera desaparecido, por innecesario.

Tras la disolución del IRA, el Reino Unido vuelve a comparecer ante Estrasburgo, esta vez en relación con dos nuevos problemas: la legislación contra el terrorismo islámico y la guerra de Irak. En A y otros contra Reino Unido, de 19 de febrero de 2009, el Estado es nuevamente condenado. Tras el ataque terrorista en Estados Unidos de 11 de septiembre de 2001, el Reino Unido se apresuró a dictar, el mismo 2001, la Anti-terrorism, Crime and Security Act, seguida de otras leyes posteriores, todas ellas con amplias restricciones sobre varios derechos humanos. El 18 de diciembre de $2001 \mathrm{el}$ Reino Unido notificó al Consejo de Europa la suspensión del artículo 15 CEDH. En este proceso, los once demandantes eran extranjeros y fueron detenidos en aplicación de la nueva legislación antiterrorista. En una larga y muy documentada sentencia, que describe el panorama del Derecho internacional (incluyendo soft law) en la materia, el Tribunal analiza de nuevo los artículos 3 y 5, añadiendo en esta ocasión la prohibición de discriminación del artículo 14; en síntesis:

a) Sobre la integridad personal. Tres de los demandantes permanecieron recluidos durante aproximadamente tres años y tres meses y los demás durante períodos más cortos. Durante gran parte de su detención, no pudieron prever en qué momento serían puestos en libertad, ni siquiera saber si lo serían algún día. Aunque el Tribunal considera verosímil que el estrés al que fueron sometidos pudo afectar a su salud mental, no se puede decir que se les priva-

42 Sakik y otros, de 26 de noviembre de 1997 (violación del art. 5.3, 5.4 y 5.5); Demir y otros, de 23 de septiembre de 1998 (violación del art. 5.3); Nuray Sen, de 17 de junio de 2003 (violación del art. 5.3); Elçi y otros, de 13 de noviembre de 2003 (violación de los arts. 3, 5.1 y 8); Sadak, de 8 de abril de 2004 (violación del art. 5.3); Yurttas, de 27 de mayo de 2004 violación de los arts. 5.3 y 10); Abdülsamet Yaman, de 2 de noviembre de 2004 (violación de los arts. 3, 5.3, 5.4 y 5.5); y Bilen, de 21 de febrero de 2006 (violación de los arts. 3, 5.3 y 5.4). 
ra de toda esperanza de liberación, en particular porque pudieron impugnar judicialmente la legalidad de su detención e incluso obtuvieron una decisión favorable de la Special Immigration Apeals Commission (SIAC) y de la Cámara de los Lores. Además, la SIAC tenía la obligación legal de revisar cada seis meses la legalidad del mantenimiento de su privación de libertad. En estas condiciones, las medidas impuestas no se asimilan al trato degradante prohibido de forma absoluta por el Convenio, y en cualquier caso, todos ellos dispusieron de las mismas vías de recurso que los demás presos, pero al no haberlas ejercido, no cumplieron con la exigencia del agotamiento previo de los recursos internos.

b) Sobre la libertad personal. El Tribunal debía primero determinar si la detención fue legal en virtud del artículo 5.1 f), que permite a los Estados restringir la libertad de los extranjeros en el marco del control de la inmigración, no bastando para ello que se encuentre en curso un procedimiento de expulsión o extradición. El artículo 5.1 exige que toda privación de libertad, además de legal, proteja a la persona contra la arbitrariedad, esto es, aplicarse de buena fe, estar estrechamente relacionada con el motivo de detención, en un lugar y condiciones apropiadas, y con la duración necesaria para lograr el fin perseguido. Yendo al caso, resulta innegable que los demandantes fueron privados de su libertad en el sentido del artículo 5.1. Se trataba de extranjeros que el gobierno habría expulsado del territorio británico si hubiese podido encontrar un país de destino sin riesgo de torturas o malos tratos. Pese a no encontrarlo, el ministro del Interior consideró que su detención era necesaria, al estimar que su presencia en territorio británico constituía un riesgo para la seguridad nacional. En situación de normalidad una persona en trámite de expulsión no podía ser legalmente encarcelada si su expulsión resultaba posible en un plazo razonable. Sin embargo, con la legislación antiterrorista la reclusión se permitía en estos casos. Parece, por tanto, que uno de los presupuestos fundamentales que justificaban la notificación de derogación, la Ley de 2001 y la decisión de recluir a los demandantes era que la imposibilidad de devolverlos o expulsarlos tenía un carácter «momentáneo». No obstante, el gobierno no demostró que un tercer Estado seguro no hubiera estado dispuesto a recibir a los demandantes; por tanto, su detención no correspondía a la excepción al derecho a la libertad prevista en el artículo $5.1 \mathrm{f})$.

La tesis del gobierno según la cual solo a él le compete la búsqueda del justo equilibrio entre la libertad individual y la protección de la población contradecía no solamente la jurisprudencia sobre el artículo 5.1 f) sino también el principio según el cual solo la interpretación estricta de las restricciones expresamente previstas resulta compatible con los fines perseguidos por el precepto. Cuando una detención se 
extralimita de lo fijado por la jurisprudencia del Tribunal no se puede restituir invocando la necesidad de sopesar los intereses del Estado y de los detenidos.

Por último, $A$ y otros se detiene en una cuestión clave a los efectos de este estudio: si la invocación del artículo 15 permite una lectura diferente a la exigida en situaciones de normalidad. En un análisis muy detallado, con cita de su jurisprudencia anterior, Estrasburgo reitera la doctrina del margen de apreciación nacional en la determinación del supuesto de hecho pero seguidamente afirma que, en este caso, el «peligro para la vida de la nación» no exigía estrictamente las medidas adoptadas para impedirlo. Lo importante de la Sentencia es que el razonamiento sobre la proporcionalidad resulta ya bastante detallado: a) frente al alegato del gobierno de que apreciar la necesidad de la reclusión es una cuestión más política que jurídica, y que por tanto corresponde al poder ejecutivo, Estrasburgo responde que, especialmente cuando están en juego los derechos humanos, «la cuestión de la proporcionalidad depende en última instancia de los tribunales»; b) aunque debe analizarse el contexto, al final el análisis de la proporcionalidad de las medidas debe hacerse caso a caso; c) en cuanto a la detención por ser los demandantes extranjeros, el TEDH pone en cuestión la aplicación de la legislación de extranjería, pues los ataques contra la seguridad nacional pueden provenir tanto de ciudadanos británicos como de extranjeros: al elegir el recurso al Derecho de extranjería para tratar un problema de seguridad pública, el ejecutivo y el legislativo dieron una respuesta inadecuada y expusieron a un grupo particular de presuntos terroristas al riesgo desproporcionado y discriminatorio de una detención de duración indeterminada, careciendo de justificación la diferencia de trato entre musulmanes británicos y musulmanes extranjeros. En conclusión, el Tribunal estima que las medidas adoptadas al amparo del artículo $15 \mathrm{CEDH}$ fueron desproporcionadas y que el Reino Unido vulneró el derecho a la libertad personal de nueve de los demandantes ${ }^{43}$. Añade después, aunque ya no resultaba necesario, que violó también el derecho a la no discriminación.

La Sentencia Hassan contra Reino Unido, de 16 de septiembre de 2014, tiene la particularidad de que en esta ocasión no se declaró ni notificó el estado excepcional. Se juzgaba el caso de una persona arrestada por las fuerzas británicas en Irak y hallada muerta con heridas de bala meses después, aunque lejos del territorio controlado por el Reino Unido. El Tribunal inadmite, por manifiestamente infundado, el análisis del artículo 3, y se centra nuevamente en el artículo 5. Recuerda que fuera del territorio británico se mantiene la vigencia del $\mathrm{CEDH}$ y constata que el fallecido estuvo bajo custodia de las autoridades británicas al menos durante diez días. El Reino Unido, pese a no haber presentado la notificación del artículo 15.3, pretende una cierta relajación en el cumplimiento del artículo 5 en caso de conflicto armado, y el

43 La sentencia es la última relevante sobre la lucha antiterrorista y refleja bien la evolución del TEDH hacia un control más estricto; para otra lectura, F. DE LONDRAS (2015): «Counter-Terrorist detention and International Human Rights Law», en B. Saul (ed.), Research Handbook on International Law and Terrorism, Cheltenham, Edward Elgar. 
Tribunal le da en parte la razón ${ }^{44}$. La ausencia de una suspensión formal ex art. 15 $\mathrm{CEDH}$ no impide tomar en consideración el contexto y las disposiciones del Derecho internacional humanitario. En este contexto, la privación de libertad exige cuando menos que sea «legal»y que no afecte al propósito fundamental del precepto, que es proteger al individuo frente a la arbitrariedad.

Respecto a las garantías procesales, el Tribunal cita el Cuarto Convenio de Ginebra, según el cual el internamiento «estará sujeto a revisión periódica, si es posible cada seis meses, por un órgano competente». Aunque podría no ser factible la intervención de un «tribunal» independiente en el sentido generalmente requerido por el artículo 5.4, al menos debe existir un «órgano competente» que proporcione las mínimas garantías de imparcialidad y de procedimiento justo para evitar la arbitrariedad. Aplicando esta doctrina al caso, el Tribunal considera que las autoridades del Reino Unido podían legítimamente decidir que Hassan, sorprendido por las tropas británicas armado y en una vivienda donde se encontraron más armas y documentos de valor para la inteligencia militar, debía ser detenido como prisionero de guerra y que su internamiento era necesario por razones imperiosas de seguridad. En conclusión, la captura y detención estaban en consonancia con los poderes de que disponía el Reino Unido en caso de conflicto armado y no fueron arbitrarias; por tanto, por trece votos contra cuatro, el TEDH declaró la no violación del $\mathrm{CEDH}$, pero nótese que nuevamente con varios magistrados disidentes.

Veamos finalmente los dos últimos grupos de casos relevantes ${ }^{45}$, relacionados con estados excepcionales, formales o materiales, en Ucrania y, de nuevo, en Turquía. Como consecuencia de la intervención del ejército ruso en una parte de su territorio, Ucrania declaró el estado de excepción y así lo notificó al Consejo de Europa en mayo de 2015; seguidamente, introdujo diversas modificaciones legislativas que afectaban seriamente a varios derechos humanos. No hay todavía sentencias sobre hechos posteriores pero ya antes de la declaración del estado de excepción se produjeron en el país importantes restricciones de derechos, en respuesta a la inestabilidad política derivada de la fuerte presencia de grupos independentistas armados cerca de la fron-

44 El caso demuestra que la articulación entre el Derecho de excepción y el Derecho de guerra no está bien definida, como se critica en F. Ní AOLÁIN (2017), «The cloack and dagger game of derogation», en E. J. Criddle (ed.), Human Rights in Emergencies, Cambridge, Cambridge University Press, pp. 124 y ss.

45 Tras el atentado terrorista de 13 de noviembre de 2015 y en aplicación de la Ley 385, de 1955 , Francia declaró el estado de emergencia, y así lo notificó al Consejo de Europa, solicitando la aplicación del art. 15 CEDH. El TEDH no ha dictado todavía ninguna sentencia sobre este caso. Con motivo de la pandemia actual, Francia no ha utilizado la Ley de 1955 (y tampoco ha enviado notificación al Consejo de Europa) sino que se ha apresurado a dictar en tiempo récord (lo que demuestra que el decreto-ley no es tan necesario), la Ley 290, de 23 de marzo de 2020, que modifica el Código de Salud Pública (Ley 3131-12) e incluye la declaración de «emergencia de salud pública»; véase p. ej., J. C. JOBART (2020), «Un nouveau droit d'exception: l'état d'urgence sanitaire créé et déclaré», Journal du Droit Administratif, art. 296. En el sitio web de la revista pueden consultarse otros artículos sobre este tema: http://www. journal-du-droit-administratif.fr/?page_id=2 
tera con Rusia. La sentencia Khlebik contra Ucrania, de 25 de julio de 2017, se centra en el derecho a la apelación, y resulta relevante pues en ella observamos una argumentación similar a la propia de los estados excepcionales, pero sin utilización expresa del artículo 15. Si bien el artículo $6 \mathrm{CEDH}$ no obliga a los Estados partes a establecer tribunales de apelación o casación, una vez creados, se debe garantizar que los procesados ante aquéllos gocen de «lo fundamental» de las garantías del artículo 6, básicamente el acceso al tribunal y una audiencia imparcial en un plazo razonable. El Tribunal no ignora las dificultades que a veces retrasan la audiencia de los casos en los tribunales nacionales y que se deben a una variedad de factores. Yendo al caso concreto, el Tribunal observa que el demandante pudo presentar un recurso contra su condena y que este recurso fue aceptado para su examen sobre el fondo. Tampoco se discute que la razón clave por la cual el caso de Khlebik no había sido examinado por el Tribunal de Apelación fue que su expediente no estaba disponible como resultado de las hostilidades en la zona que el gobierno no controlaba. La pregunta central es si Ucrania adoptó todas las medidas disponibles para que los derechos garantizados por el artículo 6 fueran efectivos en la práctica. Adoptando este enfoque, el Tribunal procede a determinar si existieron vías prácticas para proceder con el examen de la apelación del solicitante en un contexto tan excepcional. Tras analizar con detalle las diversas posibilidades (asistencia del Ombudsman, una nueva investigación y juicio y revisión de la sentencia sobre la base del material disponible), el Tribunal concluye que, dado que las autoridades examinaron debidamente la posibilidad de restaurar el expediente del demandante, estas hicieron todo lo posible para abordar la situación de Khlebik y por tanto que Ucrania no violó el artículo 6. Nótese como el razonamiento es similar al propio de un estado excepcional, pero sin que este fuera declarado como tal.

Por último, tras el intento de golpe de Estado en Turquía de 15 de julio de 2016, se declaró el estado de excepción en el país, y así se notificó al Consejo de Europa el 21 de julio, solicitando la aplicación del artículo $15 \mathrm{CEDH}$. Sobre las medidas tras el intento de golpe, el TEDH ya ha dictado cinco sentencias: Mebmet Hasan y Sabin Alpay, ambas de 20 de marzo de 2018; Kavala, de 10 de diciembre de 2019; y dos más centradas en la independencia judicial (Alparslan Altan, de 16 de abril de 2019 y $B$ as, de 3 de marzo de $2020^{46}$, que es la última hasta la fecha sobre el tema que nos

46 Veamos brevemente esta última sentencia, pero al margen, para no perder el hilo. Continuamos bajo el estado de emergencia. Entre los miles de detenidos tras el intento de golpe, según la misma sentencia, fueron investigados un total de 4.664 jueces y fiscales, entrando en prisión preventiva a la semana del golpe nada menos que 2.431. Entre julio de 2016 y mayo de 2017 fueron cesados por el Consejo Judicial como supuesto instigadores del golpe más de 4.500 jueces y fiscales turcos. En el caso, el TEDH falla que la prisión preventiva de la jueza Bas vulneró el art. 5 pues el Tribunal Supremo eliminó las garantías de inmunidad judicial con carácter retroactivo. Sin embargo, no se aprecia violación del art. 6 (se alegaba falta de independencia del tribunal que decretó la prisión). Estrasburgo hace un ejercicio de autocontención y no entra en el problema estructural de la independencia judicial en Turquía, sosteniendo que su función es resolver el caso concreto, como si no quisiera molestar demasiado al país, más cuanto se encuentra abierta una negociación entre el Consejo de Europa y Turquía sobre la 
ocupa). Me limitaré a la reseña de la primera, pues las tres que la siguen son bastante similares.

En cuanto al supuesto de hecho de aplicación del artículo 15, el Tribunal reitera su doctrina sobre el margen nacional de apreciación, aunque no ilimitado, y se remite al análisis legitimador del Tribunal Constitucional turco; Estrasburgo no dedica mucho esfuerzo a ello, pues parece obvio que un intento de golpe de estado amenaza la vida de la nación y ni siquiera las partes discutieron sobre esto. La Sentencia declara la violación de dos derechos humanos:

a) La libertad personal. El demandante, sospechoso de tener vínculos con una organización terrorista, estuvo bajo custodia policial desde el 10 de septiembre de 2016 y en prisión preventiva desde el 22 de septiembre. El 14 de abril de 2017 fue acusado formalmente por el fiscal de Estambul. Tras su condena y apelación, el 11 de enero de 2018, el Tribunal Constitucional le absolvió por falta de pruebas, recordando de paso la vigencia de la libertad personal durante el estado de excepción. Sin embargo, tras la Sentencia del Tribunal Constitucional, el Tribunal Penal de Estambul rechazó la liberación de Altan, aduciendo falta de jurisdicción del Tribunal Constitucional para evaluar las pruebas y violación de la independencia judicial y del derecho al juez predeterminado por la ley. Para Estrasburgo, el hecho de que otro tribunal cuestione la competencia de un tribunal constitucional, dotado de poderes para emitir sentencias definitivas y vinculantes, va en contra de los principios fundamentales del Estado de Derecho y de la seguridad jurídica, deduciendo sin más de ello la violación del artículo 5.1.

b) La libertad de expresión. Aunque no era necesario, pues la intervención parece ser la misma, el Tribunal analiza también la detención como una intervención disuasoria de la libertad de expresión (el demandante era periodista), y así lo consideró el propio Tribunal Constitucional turco. A partir de aquí, se sigue el análisis «canónico» (esta vez sí) de las intervenciones sobre los derechos de defensa: a) aunque hay dudas sobre su correcta aplicación al caso, la ley prevé la intervención en este tipo de supuestos; b) el objetivo era legítimo, la protección del orden público y la prevención del delito; c) sin embargo, la detención no fue necesaria ni proporcionada. Este segundo

supervisión de su política posterior al golpe de Estado de 2016, que de hecho ya ha dado algunos frutos. Una interpretación similar en T. MARINIELLO (2019), «Prolonged emergency and derogation of human rights: why the European Court should raise its immunity system», German Law Journal, n 20, p. 70. Hay un recurso masivo pendiente (Selçuk Altun contra Turquía y 545 recurrentes más, APP 60.065/16, comunicada el 17 de mayo de 2019) por hechos similares al caso Bas, por lo que Estrasburgo no tendrá más remedio que entrar en el problema estructural de fondo. Según MARINIELLO (op. cit., p. 62), hay 26.000 demandas pendientes relacionadas con el estado de excepción en Turquía; el dato no me cuadra (la fuente que cita no es correcta y no coincide con el total de casos pendientes en la web del TEDH), pero aunque solo fueran la mitad, resulta evidente que se dan los presupuestos de los llamados casos piloto. 
análisis me parece de especial significación: bajo un estado de excepción formalmente declarado, y sobre un derecho susceptible de suspensión según el $\mathrm{CEDH}$, se aplica el mismo canon de legitimidad de las intervenciones que en situaciones de normalidad constitucional. Permítame el lector transcribir este fragmento de la Sentencia Altan (cursivas mías, GER):

La existencia de un «peligro público que amenaza la vida de la nación» no debería ser el pretexto para limitar el juego libre del debate político, que es el corazón mismo del concepto de sociedad democrática. En opinión del Tribunal, incluso en estado de emergencia, que es [...] un régimen legal cuyo objetivo es volver al régimen ordinario garantizando los derechos fundamentales, los Estados partes deben tener en cuenta que las medidas a adoptar deben apuntar a la defensa del orden democrático amenazado y hacer todo lo posible para proteger los valores de una sociedad democrática, como el pluralismo, la tolerancia y el espíritu de apertura. En este contexto, el Tribunal considera que criticar a los gobiernos y publicar información que los líderes de un país consideran peligrosa para los intereses nacionales no debería conducir a la formulación de cargos penales particularmente graves, como la pertenencia o asistencia a una organización terrorista, el intento de derrocar al gobierno o el orden constitucional o la propaganda del terrorismo. Además, incluso en los casos en que existan cargos tan graves, la detención preventiva solo debe utilizarse de forma excepcional, como último recurso, cuando otras medidas no sean suficientes para garantizar realmente el correcto desarrollo de los procedimientos. [...] La detención provisional de voces críticas crea múltiples efectos negativos, tanto para la persona detenida como para la sociedad en general, porque imponer una medida que resulte en la privación de libertad, como fue el caso, inevitablemente produce un efecto disuasorio sobre la libertad de expresión al intimidar a la sociedad civil y al reducir las voces disidentes al silencio, [incluso] cuando el detenido es posteriormente absuelto.

Hasta aquí Estrasburgo, cuyo balance resulta a mi juicio bastante positivo, pues ha ido progresivamente acercándose a un control estricto, deferente pero no sustancialmente distinto al propio de las situaciones de normalidad ${ }^{47}$. De cara al futuro, interesa no obstante puntualizar que la doctrina que acabo de sintetizar se ha centrado

47 La valoración de conjunto de T. MARINIELLO (2019), «Prolonged...», cit., esp. pp. 67-71, es extraordinariamente crítica, llegando a afirmar que el TEDH ha renunciado a su papel de guardián de los derechos humanos en Europa. En realidad, la crítica se centra en cuatro aspectos, pero en mi opinión no son tan importantes: el margen de apreciación nacional del supuesto de hecho, la falta de atención a la duración de las medidas, el escaso control del procedimiento de notificación y, últimamente, las muchas inadmisiones de las demandas contra Turquía, por un exceso de celo en la aplicación del art. 35. El autor no cita el principio de proporcionalidad, que a mi juicio es la cuestión clave, y en ella la doctrina de Estrasburgo hoy sí me parece avanzada, más teniendo en cuenta que desde la literalidad del CEDH la dirección bien podría haber sido otra. Una valoración también crítica pero más moderada en M. M. ZEIDY (2003), «The ECHR and states of emergency: article 15 - A domestic power of derogation from human rights obligations», San Diego International Law Journal, vol. 4, quien se centra en las incoherencias (inevitables a mi juicio en una jurisprudencia elaborada a lo largo de seis décadas, y sobre supuestos muy variados) y en la laxitud del control realizado por Estrasburgo, o en J. P. LOOF (2010), "Crisis situations, counter-terrorism and derogation from the European Convention of Human Rights: a threat analysis», en A. Buyse (ed.), Margins of conflict: the ECHR and transitions to and from armed conlict, Antwerp, Intersentia, quien también valora esta jurisprudencia como «imperfecta» pero reconoce que 
en problemas generalizados de orden público (próximos a nuestro estado de excepción) y que seguramente deberá matizarse para los casos de salud pública ${ }^{48}$. Seguidamente vamos a comprobar, ya con mayor brevedad, que la doctrina que acabo de sintetizar se reitera en otros organismos internacionales, en una sorprendente coincidencia, reveladora de un diálogo real en materia de derechos humanos de ámbito global. Aunque de momento solo a nivel de soft law, veremos su aplicación a problemas nuevos, como los derivados de la pandemia de 2020.

\subsection{La doctrina de la Comisión de Venecia y el más reciente soft law europeo}

Con motivo de la crisis del COVID-19, en el seno del Consejo de Europa se han publicado diversos documentos, carentes todos ellos de valor jurídico vinculante, pero que ponen de manifiesto una cierta doctrina internacional, en línea con la más reciente jurisprudencia de Estrasburgo, a la que completan, siempre en el sentido de reconducir la suspensión de derechos al principio de proporcionalidad. Entre tales documentos cabe citar:

a) La compilación de la Comisión de Venecia de sus propias opiniones e informes sobre estados de emergencia, de 16 de abril de $2020^{49}$, donde se completa y amplía la doctrina de Estrasburgo, añadiendo o precisando mejor los requisitos de legalidad, temporalidad y excepcionalidad de las medidas, el carácter expreso de la proclamación del estado excepcional, y dejando aún más claro que la eventual restricción (no se habla ya de suspensión) debe someterse a los principios de necesidad y proporcionalidad. Se enfatiza además la función garantista de los estados excepcionales, bajo los cuales se refuerza el poder del Parlamento y el control judicial de las medidas. Justo en el momento de cierre de este trabajo, el 25 de mayo de 2020, la misma Comisión concluye un documento de reflexión titulado Respect for democracy, buman rights and the rule of law during states of emergency, dedicado a la pandemia actual, donde se aplican al caso los criterios generales ya mencionados, insistiendo una vez más en la centralidad del principio de proporcionalidad. Pretende diferenciar, a mi juicio como un lugar común no bien argumentado, entre limitación y derogación de derechos (\$§ 40-41), pero la distinción

la generosidad del TEDH en el margen de apreciación se compensa con un uso cada vez más estricto del principio de proporcionalidad.

48 Este es el modelo «orientado a tipos» de situaciones de emergencia propuesto por J. W. NICKEL (2017), «Two models of normative frameworks for human rights during emergencies», en E. J. Criddle (ed.), Human rights in emergencies, Cambridge, Cambridge University Press, pp. 56 y ss. Casi premonitoriamente, el autor ya nos advertía de que, p. ej., el análisis de las epidemias y pandemias iba a resultar más complejo, al requerir mucha más información que el caso tradicional del terrorismo (pp. 70-71).

49 En castellano, con presentación de J. M. CASTELLÀ ANDREU, puede verse en el nº 32 (2020) de la Revista General de Derecho Constitucional. 
me parece ficticia, pues en ambos casos se utilizan los mismos criterios de control de las medidas restrictivas.

b) El 7 de abril de 2020 el Secretario General del Consejo de Europa publica un documento informativo titulado Respecting democracy, rule of law and human rights in the framework of the COVID-19 sanitary crisis, donde se aplican los criterios ya conocidos del TEDH y de la Comisión de Venecia (aunque se citan también otros documentos) a la pandemia actual. Lo único novedoso es la advertencia de que las medidas que ahora se adopten pueden afectar a derechos no enjuiciados antes el TEDH (recordemos que este hasta ahora únicamente ha tratado sobre integridad, libertad personal, libertad de expresión y garantías judiciales), como la vida privada, las libertades de pensamiento, expresión, reunión y asociación y la protección de datos. No se distingue entre derogación formal o no formal de estos derechos, pues en todo caso deben respetarse los criterios habituales de control de las medidas restrictivas.

\section{NACIONES UNIDAS}

\subsection{El Pacto Internacional de Derechos Civiles y Politicos y su desarrollo y aplicación por su Comité de supervisión}

La Declaración Universal de Derechos Humanos de 1948 no contiene referencias a los estados excepcionales ni a la suspensión de derechos, ni tan siquiera a sus restricciones. Esta circunstancia se explica fácilmente, pues el documento no se redactó con miras a su aplicación coactiva. Habremos de esperar al Pacto Internacional de Derechos Civiles y Políticos de 1966 (PIDCP) para encontrar la primera referencia a esta cuestión, ya claramente influida por el Convenio Europeo de 1950, del que se copia casi todo. Según el artículo 4 PIDCP:

1. En situaciones excepcionales que pongan en peligro la vida de la nación y cuya existencia haya sido proclamada oficialmente, los Estados Partes en el presente Pacto podrán adoptar disposiciones que, en la medida estrictamente limitada a las exigencias de la situación, suspendan las obligaciones contraídas en virtud de este Pacto, siempre que tales disposiciones no sean incompatibles con las demás obligaciones que les impone el derecho internacional y no entrañen discriminación alguna fundada únicamente en motivos de raza, color, sexo, idioma, religión u origen social.

2. La disposición precedente no autoriza suspensión alguna de los artículos $6,7,8$ (párrafos 1 y 2), 11, 15, 16 y 18 .

3. Todo Estado Parte en el presente Pacto que haga uso del derecho de suspensión deberá informar inmediatamente a los demás Estados Partes en el presente Pacto, por conducto del Secretario General de las Naciones Unidas, de las disposiciones cuya aplicación haya suspendido y de los motivos que hayan suscitado la suspensión. Se hará una nueva 
comunicación por el mismo conducto en la fecha en que se haya dado por terminada tal suspensión.

Las diferencias esenciales con el CEDH son: el supuesto de hecho es algo más amplio; viene a exigirse una declaración formal nacional del estado excepcional; se amplía el listado de los derechos inderogables (añadiéndose la prohibición de prisión por deudas y el derecho a la personalidad jurídica, que no figuran en el CEDH, y, más importante, la libertad de pensamiento, conciencia y religión) y la prohibición de discriminación. Como en el CEDH, encontramos de nuevo el principio de proporcionalidad («en la medida estrictamente limitada a las exigencias de la situación») y la obligación de notificación al Secretario General de la organización.

El precepto fue desarrollado por el Comité de Derechos Humanos mediante la Observación General n ${ }^{\circ} 29$, de 24 de julio de $2001^{50}$ (que «reemplaza» a la $n^{0} 5$, de 1981), en la que se asume plenamente la doctrina del TEDH (aunque no se cita) y se añaden algunas consideraciones nuevas de calado, todas ellas en la línea de realizar un control aún más estricto de los Estados partes ${ }^{51}$. Así:

a) Resulta obligatorio proclamar «oficialmente» el estado de excepción, requisito considerado «esencial para el mantenimiento de los principios de legalidad e imperio de la ley cuando son más necesarios», algo que el TEDH nunca dejó del todo claro. De otro lado, y a diferencia de la práctica de Estrasburgo, la notificación «debe incluir una información detallada sobre las medidas adoptadas, una clara explicación de los motivos por los que se hayan adoptado, e ir acompañada de una documentación completa sobre las disposiciones jurídicas». La propia Observación se queja de que muchos Estados

50 El valor jurídico de estas observaciones generales, que son la «interpretación autorizada» de los tratados internacionales, no está claro, y en vez de perdernos en disquisiciones teóricas (aunque no puedo demostrar ahora esta tesis, creo que podría argumentarse que son fuente de Derecho), conviene atender a la realidad: los tribunales nacionales, al menos en España, rarísimamente las citan (no creo que haya muchos jueces que sepan siquiera que existen), por lo que en la práctica no están funcionando como documentos vinculantes. En la reciente STC 32/2019, frente a la alegación por los recurrentes (diputados de Podemos) de una observación general del Comité de Derechos Económicos, Sociales y Culturales de Naciones Unidos, nuestro Alto Tribunal elude toda referencia a ella (como si no existiera), y de paso añade algo sorprendente (y a mi juicio contradictorio con su reciente doctrina del control de convencionalidad, por todas STC 140/2018): cuando los tratados internacionales reconocen derechos, «es claro [i?] que tales preceptos no reconocen un derecho subjetivo exigible, sino que configuran un mandato para los Estados parte de adoptar medidas apropiadas para promover políticas públicas». Sin embargo, poco antes, el Tribunal Supremo (STS 1263/2018) había afirmado el valor vinculante, al menos, de los dictámenes de los comités de los tratados, argumento seguramente extrapolable a sus observaciones generales. El debate continúa abierto.

51 Para las diferencias entre el TEDH y el CDH en este campo, J. M. LEHMANN (2011), «Limits to Counter-Terrorism: Comparing Derogation from the International Covenant on Civil and Political Rights and the European Convention on Human Rights», Essex Human Rights Review, vol. 8, n ${ }^{\circ} 1$. Paradójicamente (por pretenderse universal, lo que en principio implicaría reducir exigencias), el PIDCP es más garantista que el CEDH, pero ello puede explicarse porque la actividad de la ONU es más política que jurídica, y lo primero puede ser más amplio que lo segundo. 
no cumplen siquiera con el deber de notificación, y en abstracto podría pensarse que resulta inútil; sin embargo, la experiencia demuestra que no es así, y que incluso resulta beneficiosa para los propios países, siempre que revelen una mínima calidad democrática ${ }^{52}$.

b) No se habla, como en Estrasburgo, del «margen de apreciación» para decidir si se está o no ante el presupuesto del artículo 4.1, y de hecho se critica a varios Estados (en concreto, se citan nueve) por haber suspendido derechos sin que existiera un "peligro para la vida de la nación».

c) A los derechos inderogables se suman algunos contenidos de los derechos derogables que se incorporan a los primeros, por formar parte del «derecho internacional general», a saber: el derecho de toda persona privada de libertad a ser tratada humanamente y con el respeto debido a su dignidad, a la detención «reconocida», a la no discriminación y a no sufrir deportación o traslado forzoso no justificado.

d) Aunque se afirma que la suspensión «es claramente distinta de las restricciones o limitaciones» de los derechos humanos, no se señalan las diferencias entre ambos conceptos; me resulta por ello una cláusula de estilo que no se compadece con lo que se dice a continuación: el Comité es contundente en la aplicación en los estados excepcionales del principio de proporcionalidad en toda su extensión; interesa transcribir el párrafo en cuestión (cursivas mías, GER):

La obligación de limitar cualesquiera suspensiones a las estrictamente necesarias según las exigencias de la situación refleja un principio de proporcionalidad común a las facultades de suspensión $y$ de limitación. Es más, el solo hecho de que una suspensión permisible de la aplicación de una determinada disposición pueda de por sí justificarse por las exigencias de la situación no elimina el requisito de que deba mostrarse que las medidas concretas adoptadas como consecuencia de esa suspensión son necesarias en razón de las exigencias de la situación. En la práctica, esto asegurará que ningún artículo del Pacto, por válida que sea su suspensión, sea completamente inaplicable al comportamiento de un Estado Parte.

Parece claro entonces que para las Naciones Unidas «suspensión» no solo no implica «supresión» sino que viene a ser equivalente a «restricción», pues se defiende el mismo modelo de control de ésta, a saber: previsión legal, contenido esencial, límite y principio de proporcionalidad.

e) Se realiza una enumeración de las más importantes obligaciones de Derecho internacional que permanecen vigentes en todo caso y que solo tangencialmente aparecían en algunas sentencias del TEDH, remitiéndose, para una

52 Así se demuestra en el muy documentado e interesante estudio empírico de E. HAFNERBURTON, L. R. ELFER y C. J. FARISS (2011), «Emergency and Escape: Explaining Derogations from Human Rights Treaties», en E. J. Criddle (ed.), Human Rights in Emergencies, Cambridge, Cambridge University Press, pp. 83 y ss. 
relación más amplia, a otros documentos específicos de soft law internacio$\mathrm{nal}^{53}$.

f) Se enfatiza especialmente que, aunque al igual que en el $\mathrm{CEDH}$, las garantías procesales pueden ser suspendidas, en realidad esto no es exactamente así, pues al menos su contenido mínimo (acceso a los tribunales, juicio imparcial y presunción de inocencia) permanece vigente, en tanto «constituye una obligación inherente del Pacto en su conjunto». La idea es interesante: si bien (y aun así muy limitadamente) buena parte del catálogo de los derechos puede ser suspendido (en realidad, restringido), no se puede atacar la esencia del tratado; en términos de Derecho constitucional, no se pueden «desconstitucionalizar», y a mi juicio tampoco «desfundamentalizar» los derechos.

El Comité tiene básicamente dos formas de controlar el cumplimiento del artículo $4^{54}$ : las observaciones finales sobre los informes que los Estados deben presentar cada cinco años y, si ratificaron el Protocolo Facultativo, la resolución de quejas («comunicaciones») individuales ${ }^{55}$; en lenguaje de la dogmática jurídica, estos dos procedimientos vendrían a coincidir respectivamente con las garantías objetivas y subjetivas de los derechos ${ }^{56}$.

53 Entre ellos, destacaría los Principios de Siracusa sobre la limitación o suspensión de disposiciones del PIDCP, aprobados por el Consejo Económico y Social de las Naciones Unidas el 24 de agosto de 1984.

54 Para un análisis más amplio del trabajo del Comité, por todos, D. McGOLDRICK (2004), «The interface between public emergency powers and international law», International Journal of Constitutional Law, vol. $2, \mathrm{n}^{\circ} 2$.

55 No concluyen en forma de sentencia pero por la composición del órgano y por el procedimiento seguido ante él son materialmente equivalentes; cada vez más, el «fallo» se asemeja al de una sentencia; véase p. ej. la tercera «condena» a España en Naciones Unidas (Dictamen del Comité de Derechos Económicos, Sociales y Culturales de 11 de octubre de 2019), que contiene medidas muy claras y concretas en materia de derecho a la vivienda.

56 Como guía en el proceloso mundo de la ONU, donde cohabitan numerosos órganos con competencia en el control de los estados excepcionales sigue siendo útil J. FITZPATRICK (1994), Human Rights in Crisis: the International System for Protecting Rights during States of Emergency, Filadelfia, University of Pennsylvania, pp. 82-177. Entre ellos, destacaría la labor de los relatores que monitorearon la situación de los derechos humanos durante o después de estados excepcionales en Bolivia (Héctor Gros Espiel, en 1982-1983), El Salvador (José Antonio Pastor Ridruejo, de 1981 a 1987) o Chile (Fernando Volio, de 1985 a 1987). En 1983 se creó un Relator especial sobre estados de excepción, que ha desaparecido, pero su temática es en gran parte asumida por el Relator especial sobre terrorismo, creado en 2005. Entre los numerosos documentos de soft law que ha producido (pueden verse en https://www. ohchr.org/EN/Issues/Terrorism/Pages/SRTerrorismIndex.aspx) destacaría el Informe presentado al Consejo de Derechos Humanos el 1 de marzo de 2018 (A/HRC/37/52). La Relatora, no por casualidad, es profesora y especialista en la materia, y realiza un esfuerzo interesante de clarificación conceptual: «Desde el punto de vista jurídico, la suspensión de determinadas obligaciones dimanantes de los tratados en situaciones de emergencia es distinta de las restricciones autorizadas en tiempo normal. Estas últimas pueden considerarse (en teoría) menos perjudiciales para la protección de los derechos humanos, aunque el problema de los estados de emergencia de facto en los que se recurre a la legislación y las medidas de lucha contra el terrorismo pone de manifiesto que no es así en la práctica». Es decir, parece que la 
Para entender el funcionamiento de la garantía objetiva de los derechos podemos acudir a la base de datos de Naciones Unidas UNHRI, que recopila gran parte del inmenso océano del soft law internacional. Buscando el 25 de mayo de 2020 en la materia «derechos civiles y políticos -derogación» aparecen 151 referencias a documentos del Comité, que se dividen a su vez en dos categorías: "preocupaciones / observaciones» y «recomendaciones»; trasladadas nuevamente a un lenguaje más jurídico, se corresponderían respectivamente con los conceptos de incumplimiento de una norma (el PIDCP en este caso) y de sanción derivada de dicho incumplimiento. Las «observaciones finales» a los informes periódicos presentados por los Estados partes suelen ser algo genéricas ${ }^{57}$ (un problema a sumar a sus dificultades de cumplimiento), y por ello no ayudan mucho a la hora de precisar la doctrina internacional sobre la suspensión de derechos en estados excepcionales. Tampoco resulta muy útil a estos efectos la lectura de las «preocupaciones / observaciones»; si leemos con atención las últimas dirigidas a los Estados más próximos a nuestro ámbito cultural (Europa y Latinoamérica), comprobaremos que no hacen sino aplicar a cada caso lo que ya está claramente expuesto en la Observación General, sobre todo: contenido esencial de algunos derechos, control judicial de cualquier restricción ${ }^{58}$ y principio de proporcionalidad. A veces incluso pretende ejercerse un inviable control de convencionalidad no solo sobre la ley nacional sino incluso sobre la misma Constitución 59 .

En cuanto al procedimiento de quejas individuales ante el Comité, debemos buscar en otra base de datos, significativamente denominada Jurisprudence data base ${ }^{60}$. De los 17 dictámenes de fondo (adoption of views) que hacen mención al artículo 4 (algunos solo obiter dicta), solo dos de ellos son posteriores a la Observación General de 2001, y aplican a casos concretos la doctrina que ya conocemos, sin innovaciones significativas.

suspensión es, simplemente, una restricción más intensa, pero si seguimos leyendo, comprobamos que en los casos de suspensión se aplica el mismo canon de control de las restricciones propio de las situaciones de normalidad.

57 Véanse p. ej. las Observaciones finales sobre el tercer informe periódico de Vietnam, de 29 de agosto de 2019, donde se exige armonizar la legislación interna con el Pacto y cumplir con el deber de notificación.

58 Véanse p. ej. las Observaciones finales sobre el cuarto informe periódico de Bulgaria, de 15 de noviembre de 2018, donde se enuncian los puntos más críticos de la legislación antiterrorista de 20152016, que seguramente terminarán llegando al TEDH.

59 Así, en las Observaciones finales sobre el quinto informe periódico de Uruguay, de 2 de diciembre de 2013, se critica que la regulación de los estados de emergencia de los arts. 31 y 168.17 de la Constitución es «demasiado amplia» y que no contempla expresamente derechos inderogables.

60 https://juris.ohchr.org/search/Documents. Consultado por última vez el 25 de mayo de 2020. 


\subsection{Algunos documentos recientes del soft law de las Naciones Unidas}

Con motivo de la actual crisis, el Comité de Derechos Humanos ha emitido una Declaración sobre la suspensión de obligaciones dimanantes del Pacto en relación con la pandemia de COVID-19, de 30 de abril de 2020. Días antes (el 8 de abril), la Alta Comisionada de Derechos Humanos había publicado unas Directrices esenciales para incorporar la perspectiva de derechos humanos en la atención a la pandemia por COVID-19. Ambos documentos reiteran básicamente la doctrina de la Observación General n 29, pero añaden algunas ideas nuevas:

a) Como regla, las medidas de suspensión de derechos solo proceden cuando el problema de salud pública no pueda abordarse con los instrumentos propios de la situación de normalidad.

b) Se detalla algo más el contenido y alcance de la obligación de notificación ${ }^{61}$, que debe incluir «las disposiciones derogadas y las razones de la excepción», así como el texto de la legislación adoptada. Además, los Estados deben notificar nuevamente al Secretario General la finalización del período de excepción; si este se prolonga o si el Estado deroga otras disposiciones del PIDCP, se debe presentar una notificación adicional.

c) Se añade la obligación de informar a la población afectada por las medidas de excepción de su alcance y aplicación, asegurando que la información se comunique rápidamente y en los idiomas hablados en el país.

d) Más en concreto, sobre la pandemia actual, se concreta que las medidas deben ser solo las «estrictamente requeridas por las exigencias de la situación de salud pública» y que deben ser temporales y limitadas en su cobertura geográfica y alcance. Además, deben ser las «menos intrusivas para lograr los objetivos de salud pública establecidos» y proporcionar salvaguardas que garanticen el retorno a las leyes normales cuando la situación de emergencia haya terminado.

e) Luego se señala algo sorprendente y que no debería pasar desapercibido: los límites legítimos a la libertades de movimiento (art. 12), expresión (art. 19) y reunión (art. 21) siguen las cláusulas de limitación de los preceptos que reconocen esos derechos, no del artículo 4 , y en esta tesis coincide el Relator

61 En el momento de cierre de este trabajo, trece Estados (de los 173 Estados partes del PIDCP) habían realizado la notificación del art. 4.3 PIDCP: Armenia, Chile, Colombia, Ecuador, El Salvador, Estonia, Georgia, Guatemala, Kirguistán, Letonia, Palestina, Perú y Rumania. Las notificaciones pueden verse en https://ijrcenter.org/wp-content/uploads/2020/04/ICCPR-Derogations-28.apr_.20.pdf. Sin embargo, según el COVID-19 Civic Freedom Tracker (https://www.icnl.org/covid19tracker/, consultada el 29 de mayo de 2020), 86 Estados del mundo han declarado estados excepcionales con motivo de la pandemia, aunque entre ellos figura España, que durante el estado de alarma no puede suspender derechos y por tanto no tiene obligación de notificación. 
Especial sobre libertad de expresión ${ }^{62}$. Sobre el ámbito de la comunicación, se señala que se deben evitar las sanciones penales por información falsa y, como contrapartida, los Estados deben promover la verificación independiente de los hechos y proporcionar ellos mismos información clara, confiable y basada en hechos.

f) En cuanto a las personas en situación de vulnerabilidad (entre ellas, se cita expresamente a las personas con discapacidad y a las víctimas de violencia de género), se afirma que no deben ser penalizadas por incumplir las medidas de emergencia si lo hacen para protegerse. Luego se afirma expresamente un deber específico de protección para las personas privadas de libertad ${ }^{63}$.

g) Finalmente, en cuanto a la coacción física, se afirma que todos los actos de aplicación de la ley deben cumplir con las normas y estándares internacionales, y especialmente con el principio de proporcionalidad, evitando el uso de la fuerza salvo en casos excepcionales así como el empleo del ejército para vigilar a la población. Todas las denuncias de abusos contra los derechos humanos por parte de fuerzas policiales o militares deben investigarse de inmediato.

\section{ORGANIZACIÓN DE ESTADOS AMERICANOS: EN ESPECIAL, LA DOCTRINA DE LA CORTE INTERAMERICANA DE DERECHOS HUMANOS}

En mi opinión, no solo resulta posible y deseable construir un Derecho común de los derechos humanos y fundamentales europeos, basado sobre todo en la doctrina del TEDH, sino también algo más amplio, un Derecho común de los derechos, válido de momento para Europa y Latinoamérica. Como han demostrado diversos estudios ${ }^{64}$,

62 Véase su Informe sobre la promoción y protección del derecho a la libertad de opinión y expresión: pandemias de enfermedades y la libertad de opinión y expresión, de 23 de abril de 2020, $\$ 17$.

63 Un tema que no podemos abordar aquí, y que merecería un trabajo independiente, es la suspensión de derechos sociales. Resulta significativo que el Pacto Internacional de Derechos Económicos, Sociales y Culturales, del mismo año que el PIDCP, carezca de una cláusula de suspensión similar a la incluida en este. Por su parte, curiosamente, Europa es menos garantista, pues el art. 30 de la Carta Social Europea de 1961 copia el art. $15 \mathrm{CEDH}$, pero sin derechos inderogables. Sin embargo, todo el soft law internacional producido tras la pandemia del COVID-19 insiste no solo en la plena vigencia de los derechos sociales sino incluso en su necesidad de protección reforzada: por todos, véase la Declaración del Comité de Derechos Económicos, Sociales y Culturales sobre la pandemia de enfermedad por coronavirus (COVID-19) y los derechos económicos, sociales y culturales, de 6 de abril de 2020. En la doctrina española, de momento, M. A. PRESNO LINERA (2020), «Estado de alarma por coronavirus y protección jurídica de los grupos vulnerables», El Cronista del Estado social y democrático de Derecho, $\mathrm{n}^{\circ} 86-87$, pp. 54 y ss.

64 P. ej., J. GARCÍA ROCA (2016), «El diálogo sobre derechos humanos entre el Tribunal Europeo y la Corte Interamericana», en P. Santolaya Machetti e I. Wences (coords.), La América de los 
existe ya un fructífero y prolongado diálogo, a veces incluso explícito, entre el TEDH y la Corte Interamericana de Derechos Humanos (CIDH), que sin duda facilita esta construcción más amplia, al menos en el campo de los derechos. Llegados a este punto de la exposición, apenas queda espacio para un análisis más completo del modelo de suspensión de derechos de la Organización de Estados Americanos, debiendo limitarnos a examinar si su órgano más importante en la materia, la citada CIDH, confirma o no la línea desarrollada básicamente por el TEDH y por el Comité de Derechos Humanos de las Naciones Unidas.

La regulación se encuentra en el artículo 27 de la Convención Americana de Derechos Humanos de 1969, titulado ya, correctamente, «suspensión de garantías» ${ }^{65}$, y claramente influida por sus precedentes del CEDH y del PIDCP. En síntesis, las diferencias (que son de matiz) son las siguientes: se define mejor (y de manera más limitada) el supuesto de hecho y se amplía el listado de derechos inderogables, añadiéndose ahora la protección de la familia, el derecho al nombre, a la nacionalidad, los derechos políticos y las garantías judiciales «indispensables».

La CIDH se ha ocupado del asunto sobre todo en la Opinión Consultiva 8/87, de 30 de enero de 1987, sobre el habeas corpus bajo suspensión de garantías, y en la Sentencia Zambrano Vélez y otros contra Ecuador, de 4 de julio de 2007, aunque hay otras sentencias de interés ${ }^{66}$. En esta ocasión cambiaré el tipo de exposición, y en vez de relatar

derechos, Madrid, CEPC, pp. 533 y ss. Para una reflexión sobre la posibilidad de una construcción más global, del mismo autor, «La interpretación constitucional de una declaración internacional, el Convenio Europeo de Derechos Humanos, y bases para una globalización de los derechos», Revista Europea de Derechos Fundamentales, $\mathrm{n}^{\circ}$ 6, 2005.

65 Como enseguida veremos, la propia Corte se salta la literalidad del precepto y afirma que este en realidad se está refiriendo a la restricción de derechos. Conviene transcribir el art. 27: «1. En caso de guerra, de peligro público o de otra emergencia que amenace la independencia o seguridad del Estado parte, éste podrá adoptar disposiciones que, en la medida y por el tiempo estrictamente limitados a las exigencias de la situación, suspendan las obligaciones contraídas en virtud de esta Convención, siempre que tales disposiciones no sean incompatibles con las demás obligaciones que les impone el derecho internacional y no entrañen discriminación alguna fundada en motivos de raza, color, sexo, idioma, religión u origen social. 2. La disposición precedente no autoriza la suspensión de los derechos determinados en los siguientes artículos: 3 (Derecho al Reconocimiento de la Personalidad Jurídica); 4 (Derecho a la Vida); 5 (Derecho a la Integridad Personal); 6 (Prohibición de la Esclavitud y Servidumbre); 9 (Principio de Legalidad y de Retroactividad); 12 (Libertad de Conciencia y de Religión); 17 (Protección a la Familia); 18 (Derecho al Nombre); 19 (Derechos del Niño); 20 (Derecho a la Nacionalidad), y 23 (Derechos Políticos), ni de las garantías judiciales indispensables para la protección de tales derechos. 3. Todo Estado parte que haga uso del derecho de suspensión deberá informar inmediatamente a los demás Estados partes en la presente Convención, por conducto del Secretario General de la Organización de los Estados Americanos, de las disposiciones cuya aplicación haya suspendido, de los motivos que hayan suscitado la suspensión y de la fecha en que haya dado por terminada tal suspensión».

66 La propia Corte refiere en su reciente cuadernillo de jurisprudencia sobre el tema, que después se citará, muchas otras sentencias, pero no aportan novedades significativas. La Sentencias de la CIDH son demasiado «académicas» y largas y contienen muchos obiter dicta sobre temas sobre los que no se la pregunta; p. ej., en la última, sobre la detención y agresión en comisaría a un transexual, vuelve a señalar, sin venir a cuento, que la prohibición de tratos crueles, inhumanos o degradantes es inderogable, incluso en estados excepcionales (Azul Rojas Marín y otra contra Perú, de 12 de marzo de 2020, § 140). Para una 
los documentos por separado, destacaré la doctrina contenida en ellos de manera más sistemática; las peculiaridades de cada caso concreto nos interesan menos, por encontrarse más alejadas de la realidad europea. En todo caso, aludiré únicamente a los aspectos que mayor interés revisten para la comparación, pues es evidente que esta doctrina no sirve directamente para el objetivo principal de este estudio, que es la búsqueda del concepto de suspensión en el Derecho español.

La Corte afirma que «suspensión» es algo distinto de «restricción» de derechos, pero más bien obiter dicta, sin relevancia real para la argumentación de fondo, y sin aclarar bien las diferencias entre ambas, aparte de lo obvio, que la suspensión solo cabe en circunstancias excepcionales. El propio órgano acaba de publicar su último «cuadernillo de jurisprudencia», titulado precisamente «Restricción y suspensión de derechos humanos», y por más que lo releo, sigo sin encontrar cuál es exactamente la diferencia entre los dos conceptos. Pero veamos las líneas más significativas de su doctrina sobre el artículo $27 \mathrm{CADH}$ :

a) No estamos realmente ante una suspensión de derechos propiamente dicha, ya que, siendo los derechos humanos consustanciales a la persona, «lo único que podría suspenderse sería su pleno y efectivo ejercicio»; en otras palabras, los derechos se limitan, no desaparecen.

b) Aunque no se utiliza el término «margen de apreciación», se reconoce una cierta discrecionalidad a los Estados a la hora de apreciar la existencia del supuesto de hecho, que viene a ser lo mismo.

c) Los derechos inderogables se amplían a cualquier otro contenido de los derechos propiamente derogables que afecte a la esencia de los principios democrático y del Estado de Derecho, en un atisbo de teoría absoluta del contenido esencial.

d) La convencionalidad de las medidas depende de cada caso, debiendo atenderse al carácter, intensidad, profundidad y particular contexto de la emergencia, así como de la proporcionalidad y razonabilidad que guarden las medidas respecto de ella.

Como resumen de esta apretada panorámica del sistema interamericano, más de lo mismo, sin innovaciones relevantes sobre los sistemas europeo y universal: los derechos humanos realmente no se suspenden (y así se afirma expresamente, de forma más clara que en Estrasburgo), los derechos inderogables son más de los que parecen,

exposición más amplia de su doctrina sobre nuestro tema, p. ej., G. RODRÍGUEZ (2019), «Artículo 27. Suspensión de garantías», en C. Steiner y M. C. Fuchs (eds.), Convención Americana de Derechos Humanos. Comentario, KAS, Bogotá, $2^{a}$ ed., o E. FERRER MAC-GREGOR y A. HERRERA GARCÍA (2017), «La suspensión de derechos humanos y garantías. Una perspectiva de Derecho comparado y desde la Convención Americana de Derechos Humanos», en G. Esquivel, F. Ibarra Palafox y P. Salazar Ugarte (coords.), Cien ensayos para el centenario. Constitución política de los Estados Unidos Mexicanos, t. 2, México, UNAM. 
y el principio de proporcionalidad ha de respetarse en todo caso. El más reciente soft law interamericano confirma lo dicho ${ }^{67}$.

\section{CONSECUENCIAS PARA EL DERECHO CONSTITUCIONAL}

¿Qué nos enseña en definitiva la doctrina del Derecho internacional, considerada en su conjunto pero centrada en el TEDH, que es el órgano que más directamente condiciona la interpretación del Derecho español?; ¿el concepto de suspensión de derechos que se desprende de esta doctrina sirve para nuestro ordenamiento? ${ }^{68}$ Veamos:

1) La derogación (art. 15 CEDH) o suspensión (arts. 4 PIDCP, 27 CADH y 55 $\mathrm{CE}$ ), que son términos sinónimos, no equivale a una desaparición temporal de los derechos ${ }^{69}$, pues estos continúan vigentes durante los estados excepcionales, declarados o no.

2) En circunstancias extraordinarias, como un terrorismo de especial intensidad o una pandemia, se permite una mayor discrecionalidad estatal tanto para la definición y consecución de un objetivo legítimo como para restringir determinados derechos, en aras a lograr dicho objetivo. El control, internacional o constitucional, resulta entonces algo más laxo.

3) Determinados contenidos de derechos nunca pueden ser afectados, lo que implica una suerte de asunción de la teoría absoluta del contenido esencial ${ }^{70}$.

67 Véase sobre todo la Resolución de la Comisión Interamericana de Derechos Humanos 1/2020, sobre pandemia y derechos humanos en las Américas, de 10 de abril de 2020, donde se insiste sobre todo en las obligaciones positivas sobre derechos sociales y en contextos de vulnerabilidad. En cuanto a los derechos civiles y políticos, que son los abordados en este estudio, se habla ya de «restricción o suspensión» de los derechos en situaciones de crisis, como si ambos conceptos fueran sinónimos, y después, a la hora de analizar uno a uno los derechos que pudieran verse afectados en la pandemia, se razona como si estuviéramos en una situación de normalidad. La Declaración de la Corte Interamericana de Derechos Humanos 1/20, de 20 de abril, mucho más breve, ni siquiera utiliza ya el término «suspensión».

${ }_{68}$ Mi reflexión se ciñe al Derecho español pero creo que podría servir como concepto de Derecho constitucional común, europeo y latinoamericano.

69 Por esta vez, y como ya adelanté, debemos saltarnos la interpretación literal. Lo curioso es que a veces los constituyentes que nos siguen copian hasta de nuestros errores, como sucede p. ej. en el Perú; por suerte, la doctrina es más inteligente que el tenor literal del texto: de interés, L. CASTILLO CÓRDOVA (2020), Derechos fundamentales y procesos constitucionales, vol. 1: Teoría general de los derechos

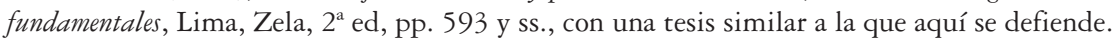

70 El contenido esencial figura en el art. 53 CE y por ello no puede ser un concepto superfluo. Se trata de un concepto que sigue sin estar claro, y para su correcta definición la doctrina del Tribunal Constitucional no sirve de mucho, pues es confusa y contradictoria. No puedo ahora detenerme en el tema, bastando con apuntar que, para que el contenido esencial resulte útil, debe entenderse en sentido absoluto, esto es, como aquella parte del contenido de los derechos (rectius, de algunos derechos) sobre la cual cualquier restricción resulta ilegítima sin más. Esta tesis se desprende de la jurisprudencia de 
4) Fuera de estos contenidos, debe analizarse siempre la proporcionalidad entre las medidas restrictivas de derechos y el objetivo pretendido con ellas (límite), que para resultar legítimo debe ser más concreto que la mera referencia al peligro para la vida de la nación (p. ej., combatir el terrorismo o evitar la propagación de una enfermedad). De esta forma, la situación de los derechos en situaciones de normalidad y de excepcionalidad no depende tanto de la declaración de un estado excepcional como de las circunstancias de cada caso ${ }^{71}$.

5) El canon de proporcionalidad utilizado es más o menos exigente pero ello tampoco depende del estado de excepción sino de la naturaleza del derecho afectado. Si atendemos a la jurisprudencia de Estrasburgo, advertimos que el análisis de la libertad personal es siempre más laxo que el análisis de libertad de expresión ${ }^{72}$, y de estos dos derechos, solo en el segundo resulta habitual encontrar los tres elementos de la versión más completa del principio de proporcionalidad, esto es, adecuación, necesidad y ponderación.

Estrasburgo, como creo haber demostrado con el ejemplo del art. 15 CEDH. En España, la última aportación que he visto (V. FERRERES COMELLA (2020), «Más allá del principio de proporcionalidad», Revista Derecho del Estado, $\mathrm{n}^{\circ}$ 46, esp. pp. 166-175) apunta bien el problema, salvo en una cosa: a mi juicio no hay derechos absolutos y derechos limitables sino contenidos absolutos y contenidos limitables de cada derecho. P. ej., el derecho a la integridad tiene un contenido absoluto (la tortura nunca puede ser legítima) y un contenido limitable (determinadas intervenciones sobre el cuerpo humano pueden ser legítimas); sobre este caso y en Estrasburgo, p. ej., correctamente S. GREER (2015), «Is the prohibition against torture, cruel, inhuman and degrading treatment really 'absolute' in International Human Rights Law?», Human Rights Law Review, vol. 15, $\mathrm{n}^{\circ} 1$. En síntesis y para explicar mejor mi tesis: resultaría absurdo analizar si la tortura fue adecuada, necesaria y ponderada, pues por atentar contra el contenido absoluto de la integridad física, resulta ilegítima por definición. De hecho, para la mayoría de la doctrina foránea, derechos absolutos (para nosotros, contenido esencial) y principio de proporcionalidad resultan conceptualmente incompatibles; por todos, G. C. N. WEBBER (2016), «Proportionality and absolute rights», en V. Jackson y M. Tushnet (eds.), Proportionality: new frontiers, new challenges, Cambridge, Cambridge University Press, pp. 75 y ss.

71 Esta es también la conclusión sobre las últimas tendencias del Derecho comparado de G. DELLEDONNE (2017), «National emergency», paper de la Max Planck Encyclopedia of Comparative Constitutional Law, disponible en línea.

72 No he encontrado un solo caso en Estrasburgo (de las más de 2.000 sentencias que declaran la vulneración del art. $5 \mathrm{CEDH}$ ) donde se analicen separadamente los tres elementos (adecuación, necesidad y ponderación) de la concepción más exigente del principio de proporcionalidad; el escrutinio se asemeja al de mera razonabilidad o, más exactamente, al control de la arbitrariedad, que es la categoría central en estos casos (aunque las diferencias entre proporcionalidad y razonabilidad tampoco están claras; p. ej., A. BARAK (2017), Proporcionalidad, Lima, Palestra, pp. 407-415). Este control en principio más laxo ha motivado recientemente la crítica del voto particular de los magistrados Valdés, Xiol y Balaguer a la STC 9/2020, si bien se entremezcla el análisis de la libertad personal con el acceso al cargo público (se trataba de la orden de prisión preventiva contra un parlamentario electo). Al margen de este caso, sugiero la siguiente explicación: la libertad personal es un derecho compuesto de diversas reglas y su naturaleza de principio (en los términos de ALEXY), que es donde juega sobre todo la proporcionalidad, queda bastante reducida. Para una explicación diferente, a cuento precisamente del art. $15 \mathrm{CEDH}$, véase J. GARCÍA ROCA (2019), «Il tempo moderato de la intervención coercitiva del Estado (artículo 155 CE) en Cataluña: un comentario a las SSTC 89 y 90/2019, en particular, proporcionalidad y test de necesidad o razonabilidad de las medidas», Teoría y Realidad Constitucional, $\mathrm{n}^{\circ} 44, \mathrm{pp}$. 518-519. 
En definitiva, no existe diferencia sustancial entre restricción ${ }^{73}$ y suspensión de derechos, sino solo de matiz, y aun así, discutiblemente ${ }^{74}$. Aunque ellos no argumentan su postura, podría coincidir con la definición de suspensión de DÍEZ-PICAZO («variedad de la restricción de derechos fundamentales») ${ }^{75}$ o de GOMES CANOTI$\mathrm{HO}$ («restricción más intensa» ${ }^{76}$. Incluso podría prescindirse del concepto sin demasiado problema, y resulta significativo que no aparezca en el último gran documento internacional de derechos humanos, la Carta de los Derechos Fundamentales de la Unión Europea ${ }^{77}$.

73 Tampoco el concepto de restricción (equivalente a intervención, afectación o injerencia) está claro en nuestra doctrina, donde frecuentemente se confunde con el límite. «Restricción» de un derecho de defensa es la acción que afecta negativamente a su contenido, y puede ser de muchos tipos: fáctica o jurídica, excepcional o estructural, individual o general. «Límite» es la justificación de esa restricción, siempre fuera del contenido esencial. P. ej., la detención durante quince días de un sospechoso de terrorismo es una restricción sobre el contenido no absoluto de su derecho de libertad, y la lucha contra el terrorismo es el límite que justifica dicha restricción.

${ }^{74}$ Otra cosa sería si entendiéramos que los límites de los derechos deben figurar expresamente en la Constitución; en ese caso, el art. 55 no resultaría superfluo, pues serviría para dar cobertura expresa a las restricciones durante los estados excepcionales. Téngase en cuenta de otro lado que, a diferencia del CEDH, el PIDESC y la CADH, el art. 55 no define el supuesto de hecho. P. ej., si entendiéramos que las manifestaciones públicas solo pueden ser prohibidas «por razones fundadas de alteración del orden público» (que es, por cierto, el único límite que literalmente permite el art. $21 \mathrm{CE}$ ), haría falta el art. 55, pero ya antes del actual estado de alarma, el Tribunal Constitucional había legitimado otros límites (p. ej., STC 42/2000), y precisamente por eso puede mirar hacia otro lado en el Auto que después se citará, y donde queda de manifiesto el uso retórico del concepto de suspensión.

75 L. M. DÍEZ-PICAZO (2013), Sistema de derechos fundamentales, Cizur Menor, Civitas, $4^{\mathrm{a}}$ ed., p. 122. Se le puede excusar la falta de argumentación, por tratarse de un tratado general, necesariamente sintético; en todo caso, el autor no cita aquí la jurisprudencia internacional. También correctamente, A. ABA CATOIRA (2011), «El estado de alarma en España», Teoría y Realidad Constitucional, no 28, p. 328, para quien también la suspensión viene a ser una forma más de restricción de derechos. La última referencia que tengo es L. COTINO HUESO (2020), «Los derechos fundamentales en tiempos del coronavirus. Régimen general y garantías y especial atención a las restricciones de excepcionalidad ordinaria», El Cronista del Estado social y democrático de Derecho, no 86-87, pp. 92-93, quien habla también de «restricción más intensa», con principio de proporcionalidad pero sin contenido esencial; con esto último no estoy de acuerdo, desde luego a la vista del TEDH y de la propia dicción del art. 53.1 CE («en todo caso»).

76 J. J. GOMES CANOTILHO (2003), Direito Constitucional e Teoría da Constituçâo, Coimbra, Almedina, $7^{a}$ ed., pp. 1105-1106. El régimen constitucional portugués es muy similar al nuestro.

77 Tampoco en la Carta Africana de los Derechos Humanos y de los Pueblos de 1981. Según F. COWELL (2013), «Sovereignty and the question of derogation: an analysis of article 15 of the ECHR and the absence of a derogation clause in the ACHPR», Birbeck Law Review, vol. 1, pp. 149-158, la ausencia de un precepto similar al art. $15 \mathrm{CEDH}$ no ha implicado en África una menor protección de los derechos humanos durante las situaciones de crisis. A mi juicio, ha sido por casualidad, pues en Estados Unidos precisamente la falta de regulación constitucional es lo que ha permitido, a juicio de muchos, que el ejecutivo haya llegado tan lejos en la restricción de derechos después del 11-S: así, P. TAPP (2019), To derogate or not to derogate, that is the question: a comparison of derogation provisions, alternative mechanisms and their implications for buman rights, Chicago, Chicago University Law School, pp. 16 y ss... aunque el Tribunal Supremo (desde Hamdi v. Rumsfeld, de 28 de junio de 2004 y las sentencias que 
Sobre la distinción entre restricción y suspensión, poco se ha avanzado desde los trabajos de ORAÁ y de DELMAS-MARTY y SOULIER, ambos de $1992^{78}$, y por tanto anteriores al giro del TEDH desde Aksoy (1996). Veamos, para concluir, sus argumentos, y de paso si pueden considerarse vigentes, a la luz de la evolución del Derecho internacional desde entonces. Los tres primeros criterios de distinción son de ORAÁ y el último de DELMAS-MARTY y SOULIER (relectura mía):

a) La justificación de las medidas que afectan a los derechos (límite): amenaza a la vida de la nación en la suspensión y otras (sobre todo, orden público, seguridad nacional, salud pública y moral) en la restricción.

b) Los derechos afectados: todos excepto algunos en la suspensión y todos en la restricción.

c) El control de las medidas: con declaración expresa de un estado excepcional en la suspensión y sin dicha declaración en la restricción.

d) El alcance temporal: limitado en la suspensión y sin límite de tiempo en la restricción.

Como se advierte, el principio de proporcionalidad no aparece citado como criterio diferenciador por ninguno de estos autores, lo que revela, aunque sea por omisión, que ya desde hace mucho tiempo se consideraba aplicable en los estados excepcionales $^{79}$. Al margen de ello, ninguno de los cuatro criterios de diferenciación utilizados por la doctrina de hace ya casi treinta años resulta hoy pertinente; así, respectivamente:

a) El límite no diferencia mucho a efectos prácticos, pues en todo caso su existencia debe ser demostrada. Si acaso, en la suspensión es más genérico, pero al final se traducirá normalmente bien en orden público bien en salud pública.

b) El contenido esencial se mantiene siempre, haya suspensión o no. En cuanto a los derechos que en el modelo europeo sí pueden ser afectados en el estado excepcional, como la libertad de expresión, el razonamiento es el mismo que para las restricciones (recordemos Altan).

c) En los tres sistemas de derechos humanos (universal, europeo e interamericano), no hay diferencia en la práctica entre declarar o no declarar el estado excepcional.

siguieron) corrigiera en parte a la Administración Bush, aproximándose algo al modelo europeo, aunque sin llegar ni mucho menos tan lejos como el TEDH.

78 J. ORAÁ (1992), Human rights in states of emergency in International Law, Oxford, Clarendon Press, esp. pp. 9-10, y M. DELMAS-MARTY y G. SOULIER (1992), «Introduction. Restraining or legitimating the reason of state», en M. Delmas-Marty y C. Chodkiewicz (eds.), The European Convention for the Protection of Human Rights: international protection versus national restrictions, Dordrecht, Martinus Nijhoff, esp. pp. 8-12.

79 Por todos, últimamente, A.-B. KAISER (2020), Ausnahme - verfassungsrecht, Tubinga, Mohr Siebeck, pp. 221-262. 
d) Si no hace falta declaración expresa, este argumento cae por su propio peso; en todo caso, la tendencia del TEDH ha sido admitir suspensiones muy prolongadas ${ }^{80}$.

En consecuencia, desde la interpretación del artículo 55 CE de conformidad con el Derecho internacional y desde el concepto de suspensión de derechos que del mismo se deriva, el debate en España sobre si durante el estado de alarma de 2020 se suspendieron o se restringieron derechos fundamentales me parece estéril ${ }^{81}$, además de peligroso para el futuro de los derechos ${ }^{82}$, pues en todo caso debe seguirse el análisis habitual de sus presuntas vulneraciones ${ }^{83}$. En otras palabras, suspensión no significa ni «desconstitucionalización» ni «desfundamentalización», y mucho menos supresión de derechos ${ }^{84}$.

80 Destacan este aspecto de la doctrina del TEDH, K. ISTREFI y S. SALOMON (2017), «Entrenched Derogations From the European Convention on Human Rights and the Emergence of Non-Judicial Supervision Derogations», Austrian Review of International and European Law, $\mathrm{n}^{\circ} 22$.

${ }_{81}$ Véase la nota 5 y, para nuevas referencias, G. LECUMBERRI BEASCOA (2020), El Derecho de excepción: una perspectiva de Derecho comparado. España: Estado de alarma, Servicio de Estudios del Parlamento Europeo, Bruselas, 2020, pp. 46-52. Con cierta resignación y bastante realismo, no faltan quienes se plantean si finalmente tiene sentido distinguir entre limitar y suspender, lo que viene a avalar la tesis que aquí se defiende: p. ej., V. ÁLVAREZ GARCÍA, F. ARIAS APARICIO y E. HERNÁNDEZ DÍEZ, Lecciones jurídicas para la lucha contra una pandemia, Madrid, Iustel, 2020, p. 101.

82 En esta dicotomía nominalista (o restricción o suspensión) incurre a mi juicio el Defensor del Pueblo, en su respuesta a las solicitudes de interposición de recurso de inconstitucionalidad, de 3 de septiembre de 2020, cuando señala: «la limitación modula el ejercicio de los derechos, la suspensión los elimina», y más adelante: «la suspensión es la destrucción, siquiera temporal, del derecho, sin margen para ponderación alguna»; en el mismo sentido, F. VELASCO CABALLERO (2020), «Libertades públicas durante el estado de alarma por la COVID-19», en D. Blanquer (coord.), COVID-19 y Derecho público, Valencia, Tirant lo Blanch, pp. 87-89, yendo incluso en contra de la ley, pues como este autor llega a reconocer, la LO 4/1981 «no permite la suspensión plena o absoluta del derecho. Y entonces se dificulta la diferencia entre una suspensión moderada y una limitación severa del derecho en cuestión». Como he pretendido demostrar, este tipo de conceptualizaciones desatiende las enseñanzas del Derecho internacional, además de implicar un grave peligro para los derechos si en el futuro se declararan los estados de excepción o de sitio, pues en ellos tales derechos desaparecerían. En todo caso, al final, aunque de forma algo rudimentaria, la clave de la resolución del Defensor del Pueblo es el principio de proporcionalidad. Para un uso más depurado de este principio, véase F. VELASCO CABALLERO, «Libertades públicas...», cit., pp. 96-105 y, derecho a derecho, pp. 114 y ss.

${ }_{83}$ Mi tesis se ve reforzada en nuestro Derecho, donde no se permite la suspensión de derechos fundamentales durante el estado de alarma: se pueden restringir, nuevamente de forma más amplia y mediante reglamento (aunque tenga rango de ley), tales derechos, pero siguiendo determinados procedimientos y con sujeción a controles específicos. Como enseguida veremos, ésta es la esencia de los estados excepcionales, resultando indiferente que los derechos se restrinjan (en el estado de alarma) o se «suspendan» (en los estados de excepción y sitio), pues lo relevante en los tres supuestos es el análisis de la proporcionalidad (y así lo confirma la LO 4/1981: correctamente, M. GONZÁLEZ BEILFUSS (2004), «La suspensión general de derechos», en L. López Guerra y E. Espín Templado (coords.), La defensa del Estado, Valencia, Tirant lo Blanch, pp. 271-274) y el correcto uso de los procedimientos y controles establecidos.

84 Quizás dos ejemplos me ayuden a explicar mejor las consecuencias prácticas de esta tesis. En el ATC 40/2020, de 30 de abril, que formalmente es de inadmisión pero que parece una sentencia de fondo, 
Si «suspensión» es solo el nombre de una forma especial de «restricción» y si los conceptos expresamente citados en la Constitución nunca pueden resultar superfluos, ¿cuál puede ser entonces el significado jurídico del concepto «suspensión de derechos fundamentales»? De un modo u otro, la práctica totalidad de la doctrina foránea afirma la misma idea: los estados excepcionales, cuando se encuentran constitucionalmente previstos y se utilizan, son una cláusula de garantía del orden constitucional, y por tanto de los mismos derechos fundamentales ${ }^{85}$. La suspensión equivale a una

se da por válida la prohibición (implícita) de una manifestación en Vigo, no tanto por el riesgo de contagio del COVID-19 como por la dificultad de circulación de ambulancias y de acceso a los hospitales. El razonamiento es muy discutible, pero lo que interesa destacar es que la clave es el principio de proporcionalidad. Pues bien, el derecho de manifestación no está suspendido (no podría hacerse en un estado de alarma) sino restringido, pero si estuviéramos en un estado de excepción propiamente dicho (donde formalmente sí cabe la suspensión de este derecho), la solución sería la misma (recuérdese, por todas, la Sentencia Altan, y en especial el párrafo antes transcrito sobre la libertad de expresión). En cuanto a la libertad de circulación, tampoco se encuentra formalmente suspendida pero quizás sí materialmente; desde la teoría absoluta podría afirmarse que se trata de un derecho sin contenido esencial, y entonces la diferencia que destaca L. COTINO HUESO (2020), «Confinamientos, libertad de circulación y personal, prohibición de reuniones y actividades y otras restricciones de derechos por la pandemia del Coronavirus», Diario La Ley, n ${ }^{\circ} 9.606$, pp. 6-8, entre suspensión y restricción desaparece, y todo vuelve a centrarse en el principio de proporcionalidad, que rige (al igual que el contenido esencial, si el derecho lo tuviera) por igual en cualquiera de los tres posibles estados excepcionales en España.

85 Entre otros muchos, para Italia, V. EBOLI (2010), La tutela dei diritti umani negli stati d'emergenza, Milán, Giuffré, esp. pp. 221-224; para Portugal, J. BACELAR GOUVEIA (2020), Estado de exceşâo no Direito constitucional, Coimbra, Almedina, pp. 73-84; entre nosotros, últimamente, E. CARMONA CUENCA (2020), «Los derechos fundamentales en el estado de alarma. La crisis sanitaria de la COVID 19 en España», en COVID 19 y parlamentarismo, México, UNAM, esp. p. 236. Un desarrollo más detallado de esta tesis se encuentra en la doctrina anglosajona: p. ej., T. R. HICKMAN (2005), «Between human rights and the rule of law: indefinite detention and the derogation model of constitutionalism», Modern Law Review, no 68, esp. p. 59, o E. CRIDDLE y E. FOX-DECENT (2010), «Human rights, emergencies and the rule of law», Human Rights Quarterly, $\mathrm{n}^{\circ} 34$ (1), donde insistentemente se señala, como objetivo del Derecho de excepción, el «garantizar a todas las personas una libertad igual y segura». Esta viene a ser también la conclusión del reciente análisis comparado de G. DELLEDONNE (2020), «Crises, emergencies and constitutional change», en X. Contiades y A. Fotiadou (eds.), Routledge Handbook of Comparative Constitutional Change, Routledge. La cuestión queda más clara si comparamos lo que algunos autores (p. ej., O. GROSS y F. Ní AOLÁIN (2006), Law in times of crisis: emergency powers in theory and practice, Cambridge, Cambridge University Press, pp. 110-172) denominan «modelo de medidas extra-jurídicas», ya en retirada, al menos en nuestro ámbito cultural. El nominalismo es mal compañero: uno de los primeros expertos en el tema, el profesor de Toronto D. DYZENHAUS (2012), «States of emergency», en M. Rosenfeld y A. Sajó (eds.), The Oxford handbook of comparative constitutional law, Oxford, Oxford University Press, pp. 451-460, habla del derogation model (que sería el europeo e interamericano) frente al suspension model (que sería el defendido en algunos votos de la minoría conservadora del Tribunal Supremo de Estados Unidos en las sentencias sobre la Patriot Act tras el 11-S), siendo la función del primero, precisamente, garantizar el Estado democrático de Derecho, y ello pese a la falta de un desarrollo completo del principio de proporcionalidad en este área. Al final, DYZENHAUS llega a la misma conclusión que aquí se defiende: siguiendo el derogation model, el párrafo segundo del art. 1.9 de la Constitución (The Privilege of the Writ of Habeas Corpus shall not be suspended, unless when in Cases of Rebellion or Invasion the public Safety may require it) se convierte en redundante. 
habilitación genérica para restringir determinados derechos fundamentales al margen de las formas y procedimientos habituales, entre ellos la reserva de ley ${ }^{86}$. Este es, a mi juicio, el sentido del concepto: reforzar el Estado democrático de Derecho, de forma tal que, en situaciones excepcionales, se fuerce al ejecutivo a declarar de forma clara y expresa las medidas que adoptará ${ }^{87}$, siguiendo una serie de procedimientos y formalidades más o menos tasadas, en última instancia para favorecer el control, en el sentido amplio del término. Si durante el estado excepcional los derechos fundamentales pueden ser restringidos por reglamento (rectius, decreto con rango de ley), es lógico que los controles se refuercen. En Francia o en Italia, por no ir muy lejos, la Constitución no menciona el término «suspensión de derechos», pero estos se ven afectados igual (en Francia, desde luego mucho más ${ }^{88}$ ) que en nuestros estados excepcionales, lo que revela de nuevo el carácter superfluo del concepto para una teoría material de los derechos fundamentales ${ }^{89}$; la diferencia reside en que, al no existir tantas cautelas procedimentales, finalmente aquéllos resultan menos protegidos, pero por cuestiones formales, no materiales.

86 Esta tesis está presente en el ATC 7/2012 y en la STC 83/2016, en cuyo FJ 9 se afirma que los reales decretos de declaración del estado de alarma pueden excepcionar, suspender o modificar la aplicabilidad de las normas con rango de ley. Que se haya hecho bien o mal (esto último se afirma en J. A. SANTAMARÍA PASTOR (2020), «Notas sobre el ejercicio de las potestades normativas en tiempo de pandemia», en D. Blanquer (coord.), COVID-19 y Derecho público, Valencia, Tirant lo Blanch, pp. 207 y ss.) es un problema complejo que no podemos abordar aquí.

87 A mi juicio y para concluir, la función principal de nuestro Derecho de excepción radica en la alteración de nuestro sistema de fuentes, habilitando al gobierno para regular materias que estarían reservadas a la ley en un contexto de normalidad; de ahí las cautelas legales en cuanto a seguridad jurídica, control parlamentario e incluso control judicial y responsabilidad patrimonial. Lo que no es poco, pero nótese que estamos en el plano de las garantías, y de hecho seguramente las restricciones a la libertad de circulación decretadas en marzo de 2020 (sub iudice) sean inconstitucionales, no tanto por cuestiones materiales (proporcionalidad) como procedimentales (se establecen las medidas del art. 20 y no las del art. 11 a) de la Ley Orgánica, es decir, se actuó en un estado de alarma como si estuviéramos en un estado de excepción). Puedo conceder que, en cierto modo, los derechos fundamentales se transforman, pero solo en una cosa: no resisten ya frente al legislador formal (antes la ley restringía los derechos) sino frente al legislador material (ahora es el reglamento quien lo hace), pero en todo caso resisten, pues las garantías judiciales nunca desaparecen.

88 En castellano, C. CERDÁ GUZMÁN (2017), «Los derechos fundamentales y la lucha contra el terrorismo: Francia bajo estado de emergencia», Revista de Derecho constitucional europeo, $\mathrm{n}^{\circ} 27$.

89 Uno de los mejores intentos de «reconceptualizar» esta materia a nivel internacional se sintetiza precisamente en la misma dirección: lo relevante de la relación entre estados excepcionales y derechos humanos no son tanto los aspectos materiales como los procedimentales: S. P. SHEERAN, (2013), «Reconceptualizing states of emergency under International Human Rights Law: theory, legal doctrine, and politics», Michigan Journal of International Law, vol. 34, $\mathrm{n}^{\circ} 3$, esp. pp. 548-557. Las ventajas quedan más claras si comparamos entre las consecuencias de regular y de no regular, como destaca G. L. NEUMAN (2017), «Constrained derogation in positive human rights regimes», en E. J. Criddle (ed.), Human rights in emergencies, Cambridge, Cambridge University Press, pp. 28-31. 
Title:

Human Rights in states of emergency and the concept of derogation of human rights

Summary:

1. APPROACH: DEROGATION OF RIGHTS, A CONCEPT IN PROGRESS. 2. COUNCIL OF EUROPE: 2.1. The European Convention on Human Rights under the interpretation of the Strasbourg Court. 2.2. The doctrine of the Venice Commission and the more recent european soft law. 3. UNITED NATIONS: 3.1. The International Covenant on Civil and Political Rights and its development and application by the Human Rights Committee. 3.2. The recent soft law in the United Nations. 4. ORGANIZATION OF AMERICAN STATES: IN SPECIAL, THE DOCTRINE OF THE INTER-AMERICAN COURT OF HUMAN RIGHTS. 5. CONSEQUENCES FOR CONSTITUTIONAL LAW.

\title{
Resumen:
}

El trabajo aplica a un caso concreto el principio de interpretación de los derechos fundamentales de conformidad con el Derecho internacional de los derechos humanos. Tras pasar revista, por orden cronológico, a los tratados internacionales más importantes a nivel universal, europeo e interamericano, así como a la doctrina que los interpreta (con especial mención a la jurisprudencia del Tribunal Europeo de Derechos Humanos), se concluye que «suspensión de derechos» es un concepto superfluo para una teoría material de los derechos fundamentales y que su utilidad se limita a reforzar sus garantías. Todos los conceptos de derechos fundamentales están relacionados; por ello, se realizan al margen algunas consideraciones sobre el contenido esencial y sobre la restricción de derechos.

\begin{abstract}
:
This article applies the principle of interpretation of fundamental rights to a specific case, in accordance with international human rights law. After reviewing, in chronological order, the most important international treaties, at the universal, european and inter-american levels, as well as the doctrine that interprets them (with special attention to the jurisprudence of the European Court of Human Rights), it is concluded that «derogation of rights» is a superfluous concept for the material theory of fundamental rights and its usefulness is limited to reinforcing their guarantees. All the concepts of fundamental rights are connected; for this reason, some considerations are made on the margin regarding the essential content and the restriction of rights.
\end{abstract}


Palabras clave:

Derechos humanos - derechos fundamentales - suspensión de derechos estados excepcionales.

Key words:

Human rights - fundamental rights - derogation of rights - states of emergency. 